\title{
New insights into Blimp-1 in T lymphocytes: a divergent regulator of cell destiny and effector function
}

\author{
Shin-Huei Fu ${ }^{1 \dagger}, \mathrm{Li}_{-T z u}$ Yeh $^{1 \dagger}$, Chin-Chen Chu ${ }^{2,3^{*}}$, B. Lin-Ju Yen ${ }^{4}$ and Huey-Kang Sytwu ${ }^{* *}$
}

\begin{abstract}
B lymphocyte-induced maturation protein-1 (Blimp-1) serves as a master regulator of the development and function of antibody-producing B cells. Given that its function in T lymphocytes has been identified within the past decade, we review recent findings with emphasis on its role in coordinated control of gene expression during the development, differentiation, and function of T cells. Expression of Blimp-1 is mainly confined to activated T cells and is essential for the production of interleukin (IL)-10 by a subset of forkhead box (Fox)p3 ${ }^{+}$regulatory $T$ cells with an effector phenotype. Blimp-1 is also required to induce cell elimination in the thymus and critically modulates peripheral T cell activation and proliferation. In addition, Blimp-1 promotes T helper (Th) 2 lineage commitment and limits Th1, Th17 and follicular helper T cell differentiation. Furthermore, Blimp-1 coordinates with other transcription factors to regulate expression of IL-2, IL-21 and IL-10 in effector T lymphocytes. In CD8 ${ }^{+} \mathrm{T}$ cells, Blimp-1 expression is distinct in heterogeneous populations at the stages of clonal expansion, differentiation, contraction and memory formation when they encounter antigens. Moreover, Blimp-1 plays a fundamental role in coordinating cytokine receptor signaling networks and transcriptional programs to regulate diverse aspects of the formation and function of effector and memory CD8 ${ }^{+} \mathrm{T}$ cells and their exhaustion. Blimp-1 also functions as a gatekeeper of T cell activation and suppression to prevent or dampen autoimmune disease, antiviral responses and antitumor immunity. In this review, we discuss the emerging roles of Blimp-1 in the complex regulation of gene networks that regulate the destiny and effector function of $\mathrm{T}$ cells and provide a Blimp-1-dominated transcriptional framework for $\mathrm{T}$ lymphocyte homeostasis.
\end{abstract}

Keywords: Blimp-1, Prdm1, Bcl-6, CD4 ${ }^{+}$T lymphocytes, CD8 ${ }^{+}$T lymphocytes, T helper cells, Regulatory T cells, T follicular helper cells, Interleukins, STATs

\section{Background}

B lymphocyte-induced maturation protein-1 (Blimp-1) ${ }^{1}$, a zinc-finger motif-containing transcriptional repressor, is encoded by the positive regulatory domain 1 gene $(\operatorname{Prdm} 1)^{1}$ and was initially characterized as a negative regulator of $\beta$-interferon (IFN- $\beta$ ) gene expression [1]. Blimp-1 was further identified as a master regulator that orchestrates plasma cell development and the

\footnotetext{
* Correspondence: chinchen.chu@gmail.com; sytwu@ndmctsgh.edu.tw ${ }^{\dagger}$ Equal contributors

2Department of Anesthesiology, Chi Mei Medical Center, Tainan 71104, Taiwan

'Department and Graduate Institute of Microbiology and Immunology, National Defense Medical Center, 161, Section 6, Min-Chuan East Road, Neihu District, Taipei 11490, Taiwan

Full list of author information is available at the end of the article
}

differentiation of immunoglobulin-secreting B lymphocytes $[2,3]$ and also controls the differentiation of the myeloid lineage [4]. The expression of Blimp-1 is dynamic in primordial germ cells and is critical for mouse embryonic development [5-7]. Generation of loss-offunction Blimp-1 mutants by gene targeting is embryonic-lethal in mice [8]. Therefore, Blimp-1 instructs diverse cell fates in the embryo and plays essential roles in multiple hematopoietic lineages.

The number of studies demonstrating the importance of Blimp-1 expression in different subsets of T lymphocytes for the regulation of immune networks has grown dramatically over recent years. Blimp-1 has been revealed as a key regulator of $\mathrm{T}$ cell homeostasis, and its ablation in $\mathrm{T}$ cells is responsible for downregulating 
expression of interleukin (IL)-10 and upregulating expression of IL-2 and gamma interferon (IFN- $\gamma$ ) $[9,10]$. Recent experiments have demonstrated that Blimp- 1 is also critical for $\mathrm{CD} 4^{+} \mathrm{T}$ helper (Th) cell differentiation. In $\mathrm{CD}_{4}^{+} \mathrm{T}$ cells, Blimp-1 inhibits Th1 differentiation [11] and opposes the formation of follicular helper $\mathrm{T}$ (Tfh) cells [12]. In contrast to the inhibition of Tfh commitment by constitutive expression of Blimp- 1 in $\mathrm{CD} 4^{+}$ $\mathrm{T}$ cells, deletion of Blimp- 1 in $\mathrm{CD}^{+} \mathrm{T}$ cells augments Tfh differentiation [13]. Blimp-1 and interferon regulatory factor 4 (IRF4) were shown to be indispensable and to cooperate to regulate the expression of IL-10 and C-C chemokine receptor 6 (CCR6) in effector regulatory $\mathrm{T}$ (Treg) cells [14]. Furthermore, Blimp-1 instructs transcriptional regulation to control the expression of IL-2, IL-21 and IL-10 in effector CD4 ${ }^{+} \mathrm{T}$ cells for the maintenance of $\mathrm{T}$ cell homeostasis [14-19]. In addition to CD4 ${ }^{+} \mathrm{T}$ cells, Blimp- 1 is also a critical component of the transcriptional program controlling the generation of heterogeneous $\mathrm{CD}^{+} \mathrm{T}$ cell populations. The importance of Blimp-1 in the formation of killer-cell lectin-like receptor G1 (KLRG1) ${ }^{\mathrm{hi}} \mathrm{IL}-7$ receptor (IL-7R) ${ }^{\mathrm{lo}}$ short-lived effector cells (SLECs), KLRG $1^{\mathrm{lo}} \mathrm{IL}-7 \mathrm{R}^{\mathrm{hi}}$ memory precursor effector cells (MPECs), effector memory (EM, KLRG1 ${ }^{\text {hi }} I L-7 R \alpha^{\text {hi }} C D 62 L^{\text {low }} C C R 7^{\text {low }}$ ) cells, central memory (CM, KLRG $1^{\text {low }}$ IL-7R $\alpha^{\text {hi }} C D 62 L^{\text {hi }} C C R 7^{\text {hi }}$ ) cells, and exhaustion of $\mathrm{CD}^{+} \mathrm{T}$ cells during immune responses has been demonstrated [20]. Moreover, Blimp-1 plays a critical role in the functions of $\mathrm{CD}^{+} \mathrm{T}$ cells including migration, cytotoxicity, survival, proliferation and cytokine production [20-22]. The genes regulated by the $B$ cell lymphoma-6 (Bcl-6)/Blimp-1 axis serve as a cardinal switch to enable cytokine secretion and effector function predominantly in $\mathrm{CD}^{+}$and $\mathrm{CD} 8^{+} \mathrm{T}$ lymphocytes [23]. These studies highlight the complexity of the transcriptional programs coordinated by Blimp-1 for the development, differentiation and effector function of $\mathrm{T}$ lymphocytes. Here, we briefly review the findings concerning the significance of Blimp-1 in $\mathrm{T}$ lymphocytes and demonstrate divergent roles for Blimp-1 in different $\mathrm{T}$ lymphocyte lineages.

\section{The expression of Blimp-1 in T cell lineages}

Blimp-1 is expressed not only in the B cell lineage but also in other cell lineages including T cells, granulocytes, macrophages, epithelial cells, retinal neurons, muscle cells and primordial germ cells [24]. In mice, the expression of Blimp-1 is detected in both $\mathrm{CD}^{+}$and $\mathrm{CD}^{+} \mathrm{T}$ cells that have the characteristics of effector and memory cells $[9,10]$.

\section{$\mathrm{CD}^{+} \mathrm{T}$ cells}

Martins et al. reported that they could detect little steady-state expression of Blimp-1 mRNA in thymocytes by reverse transcription-quantitative polymerase chain reaction. Double-negative (DN) thymocytes, CD4 singlepositive thymocytes and peripheral naïve $\mathrm{CD}_{4}^{+} \mathrm{T}$ cells expressed similar levels of Blimp-1 mRNA, which were threefold higher than the levels of Blimp-1 mRNA in double-positive (DP) thymocytes [10]. These results were similar to the results of another group who demonstrated Blimp-1 expression in DP thymocytes using microarray [25]. However, Kallies et al. did not detect any intrathymic Blimp-1 expression using a green fluorescent protein (GFP) knock-in strategy [9]. Martins et al. found that expression of Blimp-1 was higher in the memory, effector and regulatory $\mathrm{T}$ cell populations, and was induced after in vitro activation of naïve $\mathrm{CD} 4^{+} \mathrm{T}$ cells by $\mathrm{T}$ cell receptor (TCR) and/or IL-2 stimulation. The level of Blimp-1 mRNA in T cells was similar to that in lipopolysaccharide (LPS)-activated splenic plasma cells 6 days after in vitro stimulation with anti-CD3 and anti-CD28 antibodies and IL-2 [10]. Likewise, Kallies et al. demonstrated that the $\mathrm{GFP}^{+} \mathrm{CD}^{+} \mathrm{T}$ cells were $\mathrm{CD} 44^{\text {hi }}$ and mainly CD62 $\mathrm{L}^{\text {lo }}$, a cell surface phenotype indicating effector and memory $\mathrm{CD}^{+}{ }^{+} \mathrm{T}$ cells, and that these cells showed high expression of other activation markers such as CD122 and glucocorticoid-induced tumor necrosis family related gene (GITR) protein [9]. Consistent with this, Gong et al. reported that Blimp-1 protein was expressed in both $\mathrm{CD} 4^{+}$and $\mathrm{CD}^{+} \mathrm{T}$ cells after anti-CD3 stimulation and that Blimp-1 protein levels in activated $\mathrm{T}$ cells were similar to those found in LPS-activated B cells by western blot analysis. Moreover, Blimp-1 expression in both $\mathrm{CD} 4^{+}$and $\mathrm{CD} 8^{+} \mathrm{T}$ cells was detected $24 \mathrm{~h}$ after activation with anti-CD3 antibody, and it was clearly expressed after $48 \mathrm{~h}$ in culture [15]. Taken together, these findings suggest that Blimp-1 expression is mainly confined to activated $\mathrm{T}$ cells.

Kallies et al. assessed Blimp-1 expression during the differentiation of GFP knock-in mouse $\mathrm{CD} 4^{+} \mathrm{T}$ cells into effector cells; they cultured $\mathrm{CD}_{2} \mathrm{~L}^{+} \mathrm{CD} 4^{+} \mathrm{GFP}^{-} \mathrm{T}$ cells under Th1- or Th2-polarizing conditions. GFP analysis showed that Blimp-1 was induced in effector cells of both Th1 and Th2 lineages [9]. Salehi et al. sorted naive $\mathrm{CD}^{+} \mathrm{T}$ cells from Blimp-1-yellow fluorescent protein reporter mice and stimulated these cells under neutral, Th1, Th2 or Th17 conditions to analyze Blimp-1 mRNA expression at different time points. They found that cells cultured in Th1 or Th2 conditions began to express Blimp-1 sooner than cells cultured in neutral conditions but that Th1 cells expressed significantly more Blimp-1 than Th2 cells and at earlier time points. In contrast, cells cultured under Th17 conditions did not significantly upregulate Blimp-1, and only $5 \%$ of the cells expressed Blimp-1 at day 7.5 poststimulation. The differential expression of Blimp-1 during the differentiation of different Th populations was confirmed by either mRNA 
or protein analysis. Consistent with these findings, Blimp-1 was reported to be induced in Th1 and Th2 cells but not repressed in Th17 cells by transforming growth factor (TGF)- $\beta$ [26]. Moreover, Blimp-1 mRNA was also detected in Treg cells $[9,10]$. Cretney et al. examined the expression of Blimp-1 in Treg cells using GFP reporter mice and demonstrated that Blimp-1 was expressed in the subset of Foxp $3^{+}$Treg cells with an effector phenotype that produce IL-10. It was dispensable for the formation of effector Treg cells but essential for their ability to produce IL-10 [14].

\section{$\mathrm{CD}^{+} \mathrm{T}$ cells}

\section{Blimp-1 expression in different subsets of $C D 8^{+} T$ cells in mice}

Previous studies demonstrated that in vitro stimulation with anti-CD3e, anti-CD28 and IL-2 induced high levels of Blimp-1 mRNA expression in naive $\mathrm{T}$ cells with delayed postactivation kinetics $[9,10]$, suggesting that the expression of Blimp-1 is enhanced in $\mathrm{CD}^{+} \mathrm{T}$ cells when they encounter a cognate antigen. Indeed, the amount of Blimp-1 was significantly increased in antigen-specific effector $\mathrm{CD}^{+} \mathrm{T}$ cells during acute influenza virus, lymphocytic choriomeningitis virus (LCMV) or vaccinia virus infection [27-29]. When they encounter antigen, naïve $\mathrm{CD}^{+} \mathrm{T}$ cells undergo differentiation to generate KLRG $1{ }^{\text {hi }}$ IL-7R ${ }^{\text {lo }}$ SLECs and KLRG $1^{\text {lo }}$ IL-7R ${ }^{\text {hi }}$ MPECs that have different fates and potentials for memory cell development. After an infection is cleared, the MPECs will generate memory $\mathrm{CD}^{+} \mathrm{T}$ cells that can be either EM (KLRG1 ${ }^{\text {hi }} \mathrm{IL}-7 R \alpha^{\text {hi }} \mathrm{CD} 62 \mathrm{~L}^{\text {low }} \mathrm{CCR} 7^{\text {low }}$ ) or CM (KLRG1 ${ }^{\text {low }} \mathrm{IL}$ $7 \mathrm{R} \alpha{ }^{\text {hi }} \mathrm{CD} 62 \mathrm{~L}^{\mathrm{hi}} \mathrm{CCR} 7{ }^{\mathrm{hi}}$ ) cells [22]. During the acute phase of LCMV infection, the IL-7R $\alpha^{\text {low }}$ effector $\mathrm{CD}^{+} \mathrm{T}$ cells with high KLRG1 and low CCR7 mRNA expression exhibited elevated expression of Blimp-1 mRNA [30]. Blimp-1 expression was always higher in KLRG $1^{\text {hi }}$ IL-7R ${ }^{\text {lo }}$ SLECs than in KLRG1 ${ }^{\mathrm{lo}} \mathrm{IL}-7 \mathrm{R}^{\mathrm{hi}}$ MPECs and remained heightened in CM T subsets after LCMV infection [28]. In contrast to the situation during acute viral infections, during chronic viral infections, virus-specific $\mathrm{CD}^{+} \mathrm{T}$ cells undergo an altered profile of transcription and become exhausted. Blimp-1 expression was higher in virus-specific $\mathrm{CD} 8^{+} \mathrm{T}$ cells undergoing exhaustion during chronic viral infection than in antigen-specific $\mathrm{T}$ cells after acute infection, suggesting a correlation between Blimp-1 expression and exhaustion [31]. Overall, these results indicate that during virus infection, Blimp-1 expression exhibits a heterogeneous pattern in different $\mathrm{CD} 8^{+} \mathrm{T}$ cell subsets.

\section{The expression of BLIMP-1 in human $C D 8^{+} T$ cells}

In addition to mouse $\mathrm{T}$ cells, the expression of BLIMP-1 in human $\mathrm{CD}^{+} \mathrm{T}$ cells was also demonstrated in several recent studies. In $\mathrm{CD} 161^{++} \mathrm{IL}-18 \mathrm{R}^{+} \mathrm{CD}^{+}$human $\mathrm{T}$ cells, a newly identified subset of memory cells, the transcription level of BLIMP-1 was significantly higher than that in classical $\mathrm{CD} 27^{+} \mathrm{CD} 45 \mathrm{RA}^{-}$memory $\mathrm{CD} 8^{+} \mathrm{T}$ cells. This high level of BLIMP-1 expression may contribute to the differentiated effector-type features of $\mathrm{CD} 161^{++} \mathrm{IL}^{-18 R \alpha^{+}} \mathrm{CD}^{+}$human T cells [32]. Lee et al. identified a novel population of IL-6R $\alpha^{\text {hi }} C D 45 R A$ ${ }^{+/}{ }^{-} \mathrm{CCR}^{-} \mathrm{CD}^{+} \mathrm{EM} \mathrm{T}$ cells, which may serve as a reservoir of effector $\mathrm{CD}^{+} \mathrm{T}$ cells. These IL- $6 \mathrm{R} \alpha^{\text {hi }} \mathrm{CD} 8^{+} \mathrm{EM}$ $\mathrm{T}$ cells produce high levels of Th2 cytokines and GATA binding protein 3 (GATA3), and are expanded in the peripheral blood mononuclear cells of asthma patients. Moreover, they express low levels of the transcription factors T-BET, Eomesodermin (EOMES) and BLIMP-1, suggesting that they are not terminally differentiated $\mathrm{CD}^{+} \mathrm{T}$ cells [33]. In addition to different expression levels in $\mathrm{CD}^{+} \mathrm{T}$ cell subsets, HIV-1 transactivator of transcription (Tat) protein treatment enhanced the transcription of PRDM1 after T cell receptor stimulation. This effect of Tat on PRDM1 expression was inhibited by blocking integrins, indicating that Tat modulates BLIMP-1 through the interaction of integrins with their ligands [34].

\section{The effects of Blimp-1 on T cell functions}

Deletion of Blimp-1 in T cells leads to the dysregulation of $\mathrm{T}$ lymphocytes and the expression of an abnormally activated phenotype. This phenomenon is supported by evidence that Blimp-1 is necessary for normal thymocyte survival and controls T cell homeostasis. Blimp-1 is also critical for $\mathrm{T}$ helper differentiation and cytokine production.

\section{$\mathrm{CD}^{+} \mathrm{T}$ cells}

Blimp-1 is important for thymocyte development

Martins et al. observed that the numbers of immature DP thymocytes are reduced and that they are prone to apoptosis in mice with $\mathrm{T}$ cell-specific Blimp-1 deletion generated using the proximal-Lck-Cre deletion system, suggesting that Blimp-1 may function in early $\mathrm{T}$ cell maturation and that its dysfunction is responsible for survival defects in DP thymocytes [10]. In addition, Lin et al. reported that Blimp-1 modulates lymphocyte development. The number of thymocytes in 6-week-old Blimp-1 transgenic mice was increased compared with controls and was even higher in conditional knockout (CKO) mice lacking Blimp-1 in T cells. The numbers of DP thymocytes in both transgenic and CKO mice were significantly increased compared with controls, suggesting that Blimp-1 may have a complicated and stagedependent modulatory effect on thymocyte survival and/ or expansion. After stimulation through the TCR or with phorbol-12-myristate-13-acetate plus ionomycin, the proliferation of thymocytes was significantly impaired in Blimp-1-transgenic mice compared with controls. In 
contrast, it was dramatically enhanced in Blimp-1-CKO mice compared with controls, indicating a suppressive role of Blimp-1 in thymocyte proliferation [35]. Deletion of Blimp-1 under control of $\mathrm{Cd} 4$ or the proximal-Lck promoter resulted in global $\mathrm{T}$ cell defects during early thymic development. However, Blimp-1-deficient mice created using a distal-Lck-Cre system, which promotes deletion of genes during the late single-positive thymic development stage, had a normal number of thymocytes and did not show any signs of spontaneous autoimmunity [36]. Furthermore, Bach et al. showed that $\mathrm{T}$ cellspecific expression of the IL-2-inducible kinase-spleen tyrosine kinase (Itk-Syk) oncogene in mice leads to an early onset and aggressive polyclonal $\mathrm{T}$ cell lymphoproliferation. They found that high Itk-Syk expression in thymocytes induced Blimp-1-mediated premature terminal differentiation, resulting in oncogene-expressing cells being eliminated early in development [37]. Thus, Blimp-1 is required to induce cell elimination in the thymus.

\section{Blimp-1 maintains peripheral homeostasis}

Kallies et al. and Martins et al. both reported that Blimp-1 is expressed in effector and memory $\mathrm{T}$ cells. Kallies et al. generated Blimp-1-GFP knock-in mice and demonstrated that the $\mathrm{GFP}^{+} \mathrm{CD} 4^{+} \mathrm{T}$ cells were effector and memory $\mathrm{CD}^{+}{ }^{+} \mathrm{T}$ cells with high expression of activation markers such as CD122 and GITR, which accumulated in vivo and contributed to severe early-onset colitis [9]. Martins et al. showed that mice lacking Blimp-1 specifically in the $\mathrm{T}$ cell lineage had more effector $\mathrm{CD}^{+}$and $\mathrm{CD}^{+}$cells in the periphery [10]. Both mice with a $\mathrm{T}$ cell-specific deletion and $\mathrm{Rag} 1^{-/-}$mice reconstituted with $\operatorname{Prdm} 1^{\text {gfp/gfp }}$ fetal liver cells displayed a dysregulated population expansion that resulted in either $\mathrm{T}$ cell-mediated immune pathology or multiorgan infiltration, suggesting a linkage between Blimp-1 and the cell-intrinsic control of $\mathrm{T}$ cell activation and homeostasis $[9,10]$. Studies from Sytwu's group illustrated that Blimp-1 deficiency in $\mathrm{T}$ cells leads to higher numbers of activated $\mathrm{CD}^{+} \mathrm{T}$ cells, and this is associated with a homeostatic dysregulation of effector/memory $\mathrm{T}$ cells that contributes to both severe colitis in nonobese diabetic (NOD) mice and the exacerbation of autoimmune encephalomyelitis in myelin oligodendrocyte glycoprotein $(M O G)_{35-55}$-immunized mice $[35,38,39]$. Therefore, Blimp-1 is a key regulator of effector $\mathrm{T}$ cells and controls their homeostasis.

Kallies et al. reported that Blimp-1 controls T cell proliferation and apoptosis. Blimp-1-mutant $\mathrm{T}$ cells are less susceptible to apoptosis than wild-type cells: when cell death was impaired in $\operatorname{Prdm} 1^{\mathrm{gfp} / \mathrm{gfp}}$ mice, the numbers of Blimp-1-mutant $\mathrm{T}$ cells increased, suggesting a mechanism that contributes to effector $\mathrm{T}$ cell expansion in vivo.
They suggested that Blimp-1 in late-stage $\mathrm{T}$ cells controls activation-induced cell death (AICD) [9]. In contrast, Martins et al. showed that $\mathrm{CKO}$ and control $\mathrm{CD} 4^{+}$ $\mathrm{T}$ cells were similarly susceptible to AICD. They demonstrated that when naive $\mathrm{CKO} \mathrm{CD}^{+}{ }^{+} \mathrm{T}$ cells were stimulated via the TCR, more cells produced IL-2 and proliferated than in wild-type mice [10]. Lin et al. demonstrated the inhibitory function of Blimp-1 on $\mathrm{T}$ cell proliferation in Blimp-1-transgenic mice. This downregulated proliferation may be the result of Blimp-1mediated suppression of IL-2 production, because the production of IL- 2 by stimulated transgenic $\mathrm{CD} 4^{+} \mathrm{T}$ cells was significantly decreased compared with that by control cells. In contrast, IL-2 production was remarkably increased in CKO T cells, indicating that Blimp-1 critically modulates $\mathrm{T}$ cell activation and proliferation [35]. Blimp-1-deficiency in $\mathrm{T}$ cells results in both enhanced proliferation and attenuated AICD, resulting in aberrantly large numbers of activated $\mathrm{T}$ cells. However, the detailed mechanism by which Blimp-1 regulates proliferation and cell death needs further investigation.

During chronic and acute viral infections, the antiviral $\mathrm{T}$ cell response is controlled through a host-regulated process. Hua et al. identified T-bet- and Blimp-1dependent development of $\mathrm{CD}_{4}^{+} \mathrm{T}$ cells with cytotoxic potential and showed that this development was induced during influenza virus infection by antiviral type I IFNs and IL-2. Blimp-1 deficiency impaired the binding of Tbet to the Gzmb and Prf1 promoters, suggesting that Blimp-1 controls the development of $\mathrm{CD} 4^{+} \mathrm{T}$ cells with cytotoxic potential by regulating the binding of T-bet to the promoters of the genes for cytolytic molecules [40]. In addition, increasing expression of IL-10 regulates the suppression of viral-specific $\mathrm{T}$ cell responses. A recent study demonstrated that virus-specific Th1 cells with elevated and sustained Blimp-1-dependent IL-10 expression displayed reduced inflammatory function during chronic LCMV infection [41]. Another study showed that Blimp-1 is highly expressed in $\mathrm{CD}^{+}$memory $\mathrm{T}$ cells compared with naive $\mathrm{CD}^{+} \mathrm{T}$ cells and that it limits HIV-1 transcription in $\mathrm{CD}^{+}$memory $\mathrm{T}$ cell subsets, the primary reservoir of latent HIV-1 [42]. Therefore, Blimp-1 plays an important role in regulating the effector function of $\mathrm{CD} 4^{+} \mathrm{T}$ cells during viral infections to maintain $\mathrm{T}$ cell homeostasis.

\section{Blimp-1 controls $T$ cell differentiations}

Naïve $\mathrm{CD}^{+}{ }^{+} \mathrm{T}$ cells can differentiate into different effector lineages including Th1, Th2, Th17 and Treg cells that express lineage-specific transcription factors (such as T-bet, GATA3, retinoic acid-related orphan receptor (ROR)yt or Foxp3) upon environmental stimulation and in a specific cytokine milieu [43]. Using a GFP knock-in strategy to delete Blimp-1 in T cells, it was demonstrated 
that $\operatorname{Prdm} 1^{\mathrm{gfp} / \mathrm{gfp}} \mathrm{CD} 4^{+} \mathrm{T}$ cells can differentiate into Th1 and Th2 effector cells that secrete levels of IFN- $\gamma$, IL-4 and IL-10 similar to those produced by wild-type effector cells, indicating that Blimp-1 is not required for initiation of differentiation and cytokine production. These findings suggest that early $\mathrm{CD}^{+} \mathrm{T}$ cell effector differentiation is independent of Blimp-1 and that Blimp-1 expression is not essential for the acquisition of effector functions in the T-cell lineage [9]. Blimp-1 controls the differentiation of some Th cell lineages, including promoting Th2 lineage commitment by opposing the differentiation of IFN- $\gamma$-secreting Th1 cells [11], antagonizing follicular Th (Tfh) cells [12] and cooperating with IRF4 to maintain the function of Treg cells [14]. Th1 cells also express Blimp-1 to limit Tfh lineage commitment by suppressing the expression of both Bcl6 and C-X-C chemokine receptor type 5 (CXCR5), a chemokine receptor that is characterized as a signature marker for Tfh cells migrating into B-cell follicles [44, 45]. Recently, several studies reported that Blimp-1 regulates IL-17-secreting Th17 cells [26, 35, 39]. Lin et al. demonstrated that transgenic expression of Blimp- 1 in T cells attenuates autoimmune diabetes through suppression of Th17 cells, while Blimp-1 deficiency leads to an increase in Th17 cells [35]. In addition, Blimp-1 regulates and maintains homeostasis of the intestinal mucosa by limiting the numbers of Th17 cells [26]. Disruption of the IL23-Th17 axis ameliorates the severity of $\mathrm{T}$ cell-specific Blimp-1 deficiency-mediated colitis in CKO mice [39]. Elevated susceptibility to experimental autoimmune encephalomyelitis in Blimp-1-deficient mice involves increased Th1 and Th17 responses [38]. Deletion of Blimp-1 in T cells leads to the inability to suppress Th1 and Th17 cells in mice with colitis or autoimmune diabetes $[9,10,26,35,39]$. Therefore, Blimp-1 is clearly central to effector $\mathrm{CD} 4^{+} \mathrm{T}$ cell differentiation.

\section{The interplay between Blimp-1 and cytokines}

Kallies et al. and Martins et al. agree that Blimp-1deficient $\mathrm{CD}^{+}{ }^{+} \mathrm{T}$ cells produce higher levels of IL-2 and IFN- $\gamma$ but less IL-10 and IL-4 $[9,10]$ than wild-type cells. Further reports showed that the mean fluorescence intensity of IFN $-\gamma$ staining per cell in these $\mathrm{CKO} \mathrm{CD}^{+}$ $\mathrm{T}$ cells was increased, indicating that each CKO cell produces more IFN- $\gamma$. Blimp- 1 attenuates IFN- $\gamma$ production in $\mathrm{CD} 4^{+} \mathrm{T}$ cells activated in vitro under nonpolarizing conditions and in vivo [11,35,38]. Wang et al. showed that Blimp-1 is very strongly induced and plays a role in IL-2 inhibition when naive T cells are stimulated in the presence of IL-4, both in vitro and in vivo [46]. IL-2 is critical for $\mathrm{T}$ cell immunity to promote proliferation, activation and differentiation of $\mathrm{T}$ cells [47]; it induces Blimp-1 expression in activated $\mathrm{T}$ cells and inhibits its own production through the induction of Blimp-1 in a negative feedback loop $[15,16]$. Lack of Blimp-1 expression in $\mathrm{CD}^{+}$cells under the control of the proximal-Lck or $C d 4$ promoters leads to intrinsic functional defects and an increase in IL-17-producing cells in vivo, establishing a new role for Blimp-1 in regulating IL-17 production $[26,35,38,39]$. The overexpansion of Th1 and Th17 cells in CKO mice was significantly reduced by introducing a Blimp-1 transgene, supporting the crucial role of Blimp-1 in autoimmunity [35, 38]. Thymic deletion of Blimp-1 in $\mathrm{T}$ cells results in $\mathrm{T}$ cell development defects and spontaneous autoimmunity. However, peripheral deletion of Blimp-1 driven by the distal-Lck promoter led to reduced Th17 activation and reduced severity of autoimmune encephalomyelitis. Jain et al. also identified Blimp-1 as a key transcription factor induced by IL-23 to drive the inflammatory function of Th17 cells by enhancing expression of IL-23 receptor, granulocyte-macrophage colony stimulating factor and IFN- $\gamma$ in the peripheral T cells [36].

IL-21 is a pleiotropic cytokine that induces expression of Blimp-1 that is controlled by cooperation between signal transducer and activator of transcription 3 (STAT3) and IRF4 [17]. A high percentage and absolute number of IL-21-producing $\mathrm{CD} 4^{+} \mathrm{T}$ cells were observed in $\mathrm{MOG}_{35-55}$-immunized Blimp-1-deficient mice, and the numbers of central nervous system (CNS)-infiltrating Th1, Th17, IFN- $\gamma^{+} \mathrm{IL}-17 \mathrm{~A}^{+}$and IL-21 ${ }^{+} \mathrm{IL}-17 \mathrm{~A}^{+} \mathrm{CD} 4^{+}$ $\mathrm{T}$ cells were markedly increased in the brain and spinal cord of these Blimp-1 CKO mice at an early effector phase, suggesting a critical role of Blimp-1 in control of IL-21 production [38]. These findings raise the possibility that a negative feedback loop exists wherein IL-21 inhibits its own production through induction of Blimp-1; this possibility needs to be further investigated.

IL-10 is an anti-inflammatory cytokine produced by $\mathrm{CD}^{+} \mathrm{T}$ cells, Treg cells, $\mathrm{CD}^{+} \mathrm{T}$ cells, dendritic cells (DCs), macrophages and B cells [48]. IL-10-producing $\mathrm{CD} 4^{+} \mathrm{T}$ cells have been reported to be a self-regulation mechanism during viral or parasitic infections $[49,50]$. A population of effector $\mathrm{T}$ cells producing IL-10 (IL-10 ${ }^{+}$IFN $-\gamma^{+}$double producers) defined as $\mathrm{T}$ regulatory 1 (Tr1) cells is responsible for T-cell plasticity or reprogramming [51]. Blimp-1 has been implicated as a key transcription factor involved in the molecular mechanisms directing IL-10 production in effector T cells. Blimp-1deficient $\mathrm{CD}^{+}{ }^{+} \mathrm{T}$ cells produce less IL-10 $[9,10]$, and targeting tumor necrosis factor receptor 1 assembly in Blimp-1 CKO mice regulates Th1/Th17 effector status by increasing the frequency of IL-10-producing cells and the levels of IL-10 in Th1 and Th17 cells [39]. Virus-specific $\mathrm{T}$ cells self-limit their responsiveness and reduce their inflammatory function via Blimp-1-dependent IL-10 expression during chronic LCMV infection [41]. Type I interferon-mediated induction of Blimp-1, and a 
subsequent expansion of $\operatorname{Tr} 1$ cells, has been reported to limit Plasmodium-specific Tfh accumulation and to constrain antimalarial humoral immunity during blood-stage Plasmodium infection [52]. In addition, IL-27, together with TGF- $\beta$, is critical for IL-10 production in Th1-driven immune responses both in vitro and in models of infection with Toxoplasma gondii [53, 54]. Moreover, IL-23 counteracts the IL-27- and IL-12-mediated effects on Blimp-1-induced Tr1 development and stabilizes the inflammatory Th17 phenotype, leading to uncontrolled Th17 cell-driven CNS pathology [18]. TGF- $\beta$ antagonizes Blimp-1, is a key driver of IL-10 production in proinflammatory effector T cells downstream of IL-12 and IL-27, and shifts IL-10 regulation from a Blimp-1-dependent to a Blimp-1-independent pathway by inducing c-Maf in $\operatorname{Tr} 1$ cells [19]. Importantly, Blimp-1-dependent IL-10 production by Tr1 cells is a major regulator of tumor necrosis factor (TNF)-mediated inflammation [55]. In summary, these studies demonstrate an essential role for Blimp-1 in the transcriptional framework regulating the intrinsic plasticity of Th cells in an inflammatory milieu.

\section{Blimp-1 controls regulatory $T$ cell function}

Treg cells are required for peripheral tolerance, and Blimp-1 is a target of Foxp3 in Treg cells [56]. Because Treg cells are dependent on IL-2 for their maintenance, the feedback regulatory loop between Blimp-1 and IL-2 shown in activated $\mathrm{T}$ cells may also be important for Treg homeostasis.

IL-10 production by Tregs is significantly downregulated in Blimp-1-CKO mice, suggesting that Blimp-1 has a critical role in Treg function, which is important for limiting severe $\mathrm{T}$ cell-mediated immune pathology [10, 38]. However, Kallies et al. reported that Blimp-1-deficient Treg cells protect lymphopenic hosts from colitis elicited by injection of $\mathrm{T}$ cell populations depleted of Treg cells [9]. Intriguingly, Blimp-1 overexpression upregulates the suppressive ability of Treg cells in Blimp-1-transgenic or Blimp-1-CKO mice, suggesting that Blimp-1 critically modulates and rescues the expansion and functions of Tregs $[35,38]$. Importantly, the acquisition of Treg effector functions in Foxp3 ${ }^{+}$Tregs by production of IL-10 also requires the expression of Blimp-1 [14,57]. A population of follicular regulatory $\mathrm{T}\left(\mathrm{T}_{\mathrm{FR}}\right)$ cells expressing Blimp-1was identified in the germinal center, which limited Tfh cell and germinal center B cell numbers. Notably, Bcl-6 is essential for $T_{F R}$ cell formation, and Blimp-1 limits the numbers of $\mathrm{T}_{\mathrm{FR}}$ cells, suggesting that Bcl-6 coordinates with Blimp-1 to control $\mathrm{T}_{\mathrm{FR}}$ formation and homeostasis [58]. Blimp-1 was also upregulated in association with the activation of virus-reactive T-bet ${ }^{+}$Treg and with acquired expression of IL-10 in a mouse model of influenza virus infection, thereby conferring a functional specialization to an antiviral immune response [59].
Furthermore, Blimp-1, together with elevated levels of TGF- $\beta$, IL-10, IFN- $\beta$ and CXCR3, plays a crucial role in the ability of graft-infiltrating Foxp ${ }^{+}$Treg cells to maintain spontaneously induced kidney allograft tolerance in the DBA/2 $\left(\mathrm{H}-2^{\mathrm{d}}\right)$ to $\mathrm{C} 57 \mathrm{BL} / 6\left(\mathrm{H}-2^{\mathrm{b}}\right)$ mouse strain combination [60]. Therefore, upregulation of Blimp-1 is essential for modulating the immunoregulatory and effector functions of Treg cells.

\section{Blimp-1 is associated with $\mathrm{CD}^{+} \mathrm{T}$ cell exhaustion}

During chronic viral infection, both the $\mathrm{CD} 4^{+}$and $\mathrm{CD} 8^{+}$ $\mathrm{T}$ cell responses are impaired by a dysfunctional or exhausted state characterized by diminished effector function and enhanced expression of inhibitory molecules in $\mathrm{T}$ cells [61]. Higher levels of BLIMP-1 are expressed in $\mathrm{T}$ cells from patients with progressive chronic HIV infection [62] and are associated with lower levels of HIV expression in memory $\mathrm{CD}^{+} \mathrm{T}$ cells from nonprogressors [63]. BLIMP-1 is also induced in T cells stimulated by HIV-pulsed DCs and is associated at both the RNA and protein levels with other protein markers of exhaustion, including programmed death-1 (PD-1), lymphocyte activation gene-3 (LAG-3), cytolytic Tlymphocyte antigen-4 (CTLA-4) and T-cell immunoglobulin mucin-containing domain-3 (TIM-3) [64, 65]. Interestingly, expression of BLIMP-1 is translationally regulated by microRNA miR-9 [66]. Reduced levels of miR-9 in CD4. ${ }^{+}$T cells have been shown to play a functional role in the higher levels of BLIMP-1 expression in patients with progressive chronic HIV infection who have reduced IL-2 expression and generalized T-cell dysfunction, indicating a novel miR-9/BLIMP-1/IL-2 axis that is dysregulated in progressive HIV infection [62].

Elevated expression of IL-10 mediated by Blimp-1 is involved in the suppression of viral-specific $\mathrm{T}$ cell responses during the course of chronic LCMV infection [41]. In addition, Blimp-1 is a critical regulator of CD4 T cell exhaustion with elevated levels of inhibitory factors being expressed during chronic toxoplasmosis [67]. Therefore, Blimp-1 is highly upregulated in exhausted CD4 ${ }^{+} \mathrm{T}$ cells.

\section{$\mathrm{CD}^{+} \mathrm{T}$ cells}

\section{The effects of Blimp-1 on $\mathrm{CD}^{+} T$ cell differentiation}

Over recent years, the functions of Blimp-1 in programming the differentiation of $\mathrm{CD}^{+} \mathrm{T}$ cells have been gradually established. During acute LCMV infection, a deficiency of Blimp-1 in activated $\mathrm{CD}^{+} \mathrm{T}$ cells (Prdm $1^{\text {flox/flox }}$ GzB-cre ${ }^{+}$mice) disturbs the normal expression of several cytolytic molecules. Blimp-1-deficient $\mathrm{CD}^{+} \mathrm{T}$ cells acquired mature memory features including enhanced survival, proliferation potential, IL-2 production and increased formation of KLRG $1^{\text {lo }} I L-7 R^{\text {hi }}$ MPECs as well as $\mathrm{CD}^{2} \mathrm{~L}^{\mathrm{hi}} \mathrm{CM} \mathrm{CD}^{+} \mathrm{T}$ cells at early 
time points after infection. In addition, in the absence of Blimp-1, the transition rate from effector to memory cells was increased, indicating that Blimp-1 is critical in the development of $\mathrm{CD}^{+} \mathrm{T}$ cells during viral infection at stages from terminal differentiation to memory cell maturation [28]. During chronic infection, virusspecific $\mathrm{CD}^{+} \mathrm{T}$ cells become exhausted and accompanied by a hierarchical loss of effector function and sustained expression of several inhibitory molecules. In exhausted $\mathrm{CD}^{+} \mathrm{T}$ cells, Blimp-1 plays an important role in the regulation of expression of inhibitory molecules including PD-1, 2B4, LAG-3 and CD160, indicating that it has a role in controlling $\mathrm{T}$ cell exhaustion during chronic viral infection. Moreover, Blimp-1 functions as a transcriptional rheostat that intrinsically regulates the effector function and the exhaustion of $\mathrm{CD}^{+} \mathrm{T}$ cells at low and high expression levels, respectively [31]. In addition to its role during viral infection, Blimp-1 also affects effector $\mathrm{CD}^{+} \mathrm{T}$ cell differentiation during $\mathrm{DC}$ vaccination. However, the expansion of $\mathrm{CD}^{+} \mathrm{T}$ cells and the formation of functional memory $\mathrm{T}$ cells is not affected in Blimp-1-deficient OT-I cells responding to DC vaccination, suggesting a critical role for Blimp-1 in the formation of SLECs but not MPECs in the absence of inflammation [68].

IRF4 directly binds to the regulatory elements of Prdm1 to control Blimp-1 expression. During Listeria monocytogenes infection, Irf4 ${ }^{-/-} \mathrm{CD}^{+} \mathrm{T}$ cells retained a "precursor-like" state with impaired acquisition of an effector phenotype that was similar to that of Prdm1 ${ }^{-/-} \mathrm{CD}^{+} \mathrm{T}$ cells, suggesting that IRF-4 functions upstream of Blimp-1 in the development of protective effector $\mathrm{CD}^{+} \mathrm{T}$ cells during an immune response against an intracellular bacterium [69]. During virus infection, signals via costimulatory molecules and cytokines are critical for the generation of effector $\mathrm{CD}^{+} \mathrm{T}$ cells. After virus clearance, downregulation of costimulatory and cytokine receptors may promote apoptosis of the effector population. Blimp-1 can recruit the histone-modifying enzymes G9a and histone deacetylase 2 (HDAC2) to the regulatory elements of Il2ra and $C d 27$, thereby repressing the expression of these genes, further dictating the fate of effector $\mathrm{CD}^{+} \mathrm{T}$ cells [70]. Previous studies established a critical role for Blimp-1 in integrating inflammation and antigen signaling during effector $\mathrm{T}$ cell priming. Recently, Stelekati et al. demonstrated that the negative impact of persistent LCMV infection on

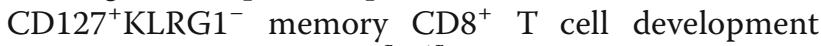
was abolished in $P r d m 1^{\text {flox/flox }}$ Gzmb-Cre OT1 cells, suggesting that Blimp-1 regulates memory $\mathrm{CD}^{+} \mathrm{T}$ cell differentiation in the presence of bystander chronic infection and prolonged inflammation [71].

\section{The effects of Blimp-1 on effector functions of $C D 8^{+} T$ cells} Blimp-1, Bcl-6, T-bet and Eomes orchestrate a transcriptional program that regulates the differentiation of effector and memory $\mathrm{CD}^{+} \mathrm{T}$ cells. In addition to cell differentiation, Blimp-1 is required for the function of cytotoxic T cells. Kallies et al. demonstrated that Blimp1 is required for the migration of viral antigen-specific $\mathrm{CD}^{+} \mathrm{T}$ cells from lymph nodes into the lungs during influenza virus infection. They observed that Blimp-1deficient $\mathrm{T}$ cells had decreased and elevated expression of lung-homing CCR5 and lymph organ-localizing CCR7, respectively, suggesting that Blimp-1 suppresses CCR7 expression to control the efficient trafficking of $\mathrm{CD}^{+} \mathrm{T}$ cells from lymph nodes to peripheral tissues [27]. Blimp-1 is also required for the cytotoxic function of $\mathrm{CD}^{+}{ }^{+} \mathrm{T}$ cells. Conditional deletion of Blimp-1 in activated $\mathrm{CD}^{+} \mathrm{T}$ cells $\left(\operatorname{Prdm} 1^{\text {flox/flox }}\right.$ Gzmb-Cre) did not affect the production of effector cytokines and CD107a but attenuated the granzyme $\mathrm{B}$ expression and cytotoxicity of viral antigen-specific $\mathrm{CD} 8^{+} \mathrm{T}$ cells during chronic infection [31]. Rutishauser et al. also observed that Blimp-1-deficient cytotoxic $\mathrm{T}$ cells had decreased granzyme B expression after acute LCMV infection. Moreover, their results revealed that the percentage of polyfunctional (IFN- $\gamma$, TNF- $\alpha$ and IL-2 triple cytokine-

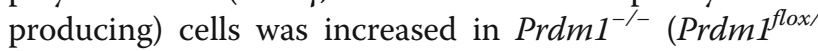
flox $\mathrm{GzB}$-Cre) mice. In addition to altering effector molecule expression, Blimp-1 antagonized the proliferation of virus-specific effector $\mathrm{CD} 8^{+} \mathrm{T}$ cells stimulated by viral antigens and homeostatic cytokines [28].

Inhibitor of DNA binding 3 (Id3) is expressed by effector $\mathrm{CD}^{+} \mathrm{T}$ cells and supports their survival during the effector-to-memory cell transition. Ji et al. demonstrated that Blimp-1 triggers the death of terminally differentiated $\mathrm{CD} 8^{+} \mathrm{T}$ cells through directly repressing $\mathrm{Id} 3$ expression and consequently increasing E2A transcriptional activity [29]. It is well established that CD25, a subunit of the IL-2 receptor, and CD27, a costimulatory molecule in the TNF receptor family, play important roles in regulating $\mathrm{CD}^{+}$responses, proliferation and survival during the different stages of viral infection [72-75]. Blimp-1 acts as an epigenetic regulator to control the chromatin state of $C d 25$ and $C d 27$ by recruiting histone-modifying enzymes G9a and HDAC2, but not Ezh2, in $\mathrm{CD}^{+} \mathrm{T}$ cells at the peak of the response to LCMV infection, suggesting that Blimp-1 downregulates cytokine receptor expression to promote the death of effector cells [70].

In contrast to its function as a repressor, Blimp-1 can also function as an enhancer of IL-10 production. During influenza virus infection, antiviral $\mathrm{CD}^{+}$cytotoxic $\mathrm{T}$ lymphocytes produce IL-10 to prevent excess inflammation [76]. Sun et al. demonstrated that $\mathrm{CD}^{+} \mathrm{T}$ cellproduced IL-2 and innate cell-derived IL-27 act 
synergistically via Blimp-1 to amplify IL-10 production in $\mathrm{CD}^{+} \mathrm{T}$ cells in the respiratory tract during influenza virus infection [77]. Moreover, the authors recently demonstrated that type I interferons can enhance the synergistic effect of IL-2 and IL-27 to promote Blimp-1mediatedI L-10 production by effector $\mathrm{CD} 8^{+} \mathrm{T}$ cells during influenza infection [78].

\section{Transcriptional regulation of Blimp-1 in T cells}

Blimp-1 in T cells is induced upon activation. Blimp-1 is associated with an abundance of chromatin-modifying enzymes that induce epigenetic changes at specific targets or recruit corepressor complexes to mediate gene silencing to regulate diverse cell fates [24].

\section{$\mathrm{CD}^{+} \mathrm{T}$ cells}

\section{Transcriptional control of Blimp-1 in CD4 $4^{+} T$ cells}

It has been reported that nuclear factor- $\mathrm{K} B$ signaling is required for induction of Prdm1 expression in B cells [79]. In addition, the BTB and CNC homology 2 (Bach2) protein functions mainly to repress Blimp-1 in B cells [4]. Recently, Bach2 was shown to be expressed also in $\mathrm{T}$ cells and to function as a critical regulator suppressing EM-related genes in naive T cells [80]. The expression of Bach2 mRNA is high in CD4 single-positive thymocytes, Foxp $3^{+} \mathrm{CD} 4$ single-positive thymocytes, naïve $\mathrm{T}$ cells, splenic $\mathrm{CD}^{+}$and $\mathrm{CD}^{+} \mathrm{T}$ cells, and Treg cells in the spleen, but very low in DN, DP and CD8 single-positive thymocytes $[80,81]$. Although the protein expression of Bach2 in naive $\mathrm{T}$ cells is high, it is lower than that in $\mathrm{B}$ cells [80]. Bach2 plays crucial roles in $\mathrm{CD} 4^{+} \mathrm{T}$ cell differentiation, generation of EM T cells and survival and development of Treg cells by regulating the effector and differentiation transcriptional program. Blimp-1, upregulated in EM T cells, is repressed by Bach2 in T cells, consistent with its repression by Bach2 in B cells [80-82]. The level of Prdm1 expression was elevated in Bach2 $2^{-/}$ Treg cells or naive $\mathrm{Bach}^{-1-} \mathrm{CD} 4 \mathrm{~T}$ cells after TCR stimulation [80, 82]. Binding of Bach2 to Prdm1 was measured in induced Treg cells by chromatin immunoprecipitation with massively parallel sequencing (ChIPSeq) [81]. Bach2 protein functions mainly to repress Blimp-1 in $\mathrm{T}$ cells to regulate $\mathrm{T}$ cell homeostasis, activation and differentiation. Other studies have also indicated that the abundance of Blimp-1, and consequently the secretion of proinflammatory cytokines, is regulated by enhancing miR-9 expression to target the 3 ' untranslated region of Prdm1 upon TCR activation $[62,66]$. Together, these data indicate that Blimp-1 can be regulated at transcriptional and posttranscriptional levels.

\section{Transcriptional involvement of Blimp-1 in effector $T$ cells}

Blimp-1 is expressed in memory and effector populations of $\mathrm{T}$ cells $[9,10]$. Blimp-1 antagonizes the expression of $\mathrm{Bcl}-6$ to regulate the effector function and differentiation program not only of $\mathrm{B}$ cells but also of $\mathrm{T}$ cells [23]. Martins et al. reported that Blimp-1 CKO $\mathrm{CD}^{+}$effector $\mathrm{T}$ cells had twice the abundance of Bcl6 mRNA transcripts as did control effector cells, indicating that Bcl-6 repression was impaired in Blimp-1deleted $\mathrm{CD} 4^{+}$effector T cells [10]. Moreover, Bach2 suppresses the EM-related expression of ST-2, Blimp-1, IL10 and S100a to maintain the naïve status of T cells in a cell-intrinsic manner. Expression of these EM-related proteins was upregulated in Bach2 $2^{-/-}$naive $\mathrm{T}$ cells [80]. Therefore, Blimp-1 is a critical component in the complex genetic programs that control effector and memory lymphocytes.

\section{Cooperation of Blimp-1 with transcription factors in $T$ helper differentiation}

An emerging role of Blimp-1 is to regulate differentiation programs in T cells. The Bcl- 6 and Blimp-1 regulatory axis is critical for $\mathrm{B}$ cell differentiation, while Blimp1 expression is repressed by Bcl- 6 in mature B cells. In T cells, Blimp-1 also functions as an antagonistic transcription factor because Blimp-1 expression is suppressed when Bcl-6 expression is initiated [10]. Initial reports have indicated high levels of Bcl-6 expression in the Tfh cells responsible for the antigen-specific regulation of B cell immunity, while high levels of Blimp-1 are expressed in non-Tfh cells [12, 23, 83].

Bcl-6 is involved in Th1 differentiation by repressing Th2 cytokine expression via decreasing GATA3 protein levels [84] and repressing IL-5 transcription [85]. In contrast to Bcl-6, Blimp-1 counteracts Th1 differentiation during Th2 lineage commitment by directly binding to Ifng, Tbx21 and Bcl6 genes. Blimp-1 mRNA and protein are more highly expressed in Th2 cells than in Th1 cells, and mice lacking Blimp-1 in $\mathrm{CD} 4^{+} \mathrm{T}$ cells exhibit impaired humoral Th2 responses. However, Bcl- 6 mRNA is more highly expressed in Th1 cells than in Th2 cells [11]. In addition, Bach $2^{-/-}$naive $\mathrm{T}$ cells have increased expression of IL-4, IL-10, Blimp-1 and GATA3, suggesting that a lack of the Blimp-1 repressor in T cells predisposes them to differentiate into Th2 cells [80]. The suppressive effect of Blimp-1 in Th1 cells is supported by evidence that transgenic Blimp-1 expression in T cells attenuates Th1 cell expansion through downregulation of Tbx21 and Ifng [35]. Other studies also indicated that Blimp-1 is able to bind to at least one site in the $I l 17 a$ gene in Th2 cells but that this is not sufficient to downregulate $I l 17 a$ transcription in cells stimulated under Th17 conditions [26]. Blimp-1 is reported to impede the development of Th17 cells via Rora and Rorc downregulation after transgenic Blimp-1 expression in Blimp-1 deficient $\mathrm{T}$ cells under control of the proximal- $L c k$ promoter [35]. However, peripheral deletion of Blimp-1 
resulted in reduced Th17 activation, and IL-23-induced Blimp-1 was found to colocalize with RORyt, STAT3 and p300 at the Il23r, Ill $\mathrm{Aa} / \mathrm{f}$ and Csf2 cytokine genes to enhance their expression and to drive the inflammatory function of Th17 cells [36]. The mechanism by which Blimp-1 regulates Th17-mediated immunopathology depends on the model that is used, and it causes either thymic $\mathrm{T}$ cell developmental defects or deletion of genes during the late SP thymocyte developmental stage that continues in peripheral $\mathrm{T}$ cells.

Bcl-6 orchestrates Tfh cell lineage commitment to support B cell maturation into antibody-producing cells [86], whereas Blimp-1 functions as an antagonistic transcription factor to oppose Tfh cell differentiation [12]. Fazilleau et al. demonstrated that the differentiation and diversity of effector Tfh cells in vivo was related to the strength of TCR binding. Expression of Blimp-1 distinguished "lymphoid" Th effector cells $\left(\mathrm{CD} 62 \mathrm{~L}{ }^{\text {hi }}\right.$ CCR 7 hi $)$ from those Bcl-6-expressing CXCR 5 hi "resident" effector Tfh cells $\left(\mathrm{CD} 62 \mathrm{~L}^{\mathrm{lo}} \mathrm{CCR} 7^{\mathrm{lo}}\right)$ by high expression of IL-4, IL-21 and PD-1 after stimulation with TCR of higher affinity [83]. Multiple signals are involved in negatively regulating Tfh cells. Recent studies have reported that STAT5 signaling, induced by IL-2, negatively regulates Tfh cell differentiation and controls humoral immunity and $\mathrm{B}$ cell tolerance by upregulating Blimp-1 to repress Bcl6 expression, suggesting that the IL-2/STAT5 axis functions to regulate Blimp-1 expression [87, 88]. It has been reported that there is a flexibility between Th1 and Tfh-like gene expression patterns as a result of strong IL-2 signaling that decreases the ratio of Bcl-6 to T-bet and controls the Bcl-6-Blimp-1 axis, leading to Blimp-1mediated repression of Tfh signature genes in effector Th1 cells [45]. Another transcription factor, Kruppel-like factor 2 (KLF2), binds to the promoter region of Prdm1 and restricts Tfh cell differentiation by inducing Blimp-1 to inhibit Bcl-6 expression after $\mathrm{T}$ cell activation [89]. Notably, recent studies have demonstrated a critical role for $\mathrm{T}$ cell factor 1 (TCF-1) function upstream of the Bcl6-Blimp-1 axis to direct the differentiation of the Tfh lineage [90-92]. After viral infection, effector $\mathrm{CD}^{+} \mathrm{T}$ cells differentiate into TCF- $1^{\text {high }}$ Blimp- $1^{\text {low }}$ Tfh and TCF- $1^{\text {low }}$ Blimp- $1^{\text {high }}$ Th1 cells. In the absence of TCF-1, cells were unable to maintain the transcriptional and metabolic signatures of Tfh cells and displayed an abnormal "Th1-like" gene expression profile with increased expression of Il2ra and Prdm1, which limit the Tfh response [91]. TCF-1 was also found to bind directly to the Bcl6 promoter and Prdm1 5' regulatory regions, resulting in activation of Bcl-6 but repression of Blimp-1 [92]. Downregulation of TCF-1 binding to the Prdm1 intron leads to upregulation of Blimp-1 and Blimp-1mediated repression of Bcl-6 in Th1 cells, while its retention on the upstream region of Bcl6 in Tfh cells results in upregulation of Bcl-6 and suppression of Blimp-1 during Tfh differentiation [90]. Consequently, the balance between Bcl- 6 and Blimp-1 expression in T cells plays an essential role in regulating $\mathrm{T}$ cell differentiation.

Transcriptional regulation of Blimp-1 in cytokine production Blimp-1 is also crucial for inducing cytokine production by inflammatory $\mathrm{T}$ helper cells and effector Treg cells.

The gene encoding IL-2 is one of the most important genes targeted by Blimp- 1 in T cells, because IL- 2 production is indispensable for $\mathrm{T}$ cell proliferation and differentiation. The relationship between IL-2 and Blimp-1 was reported as a negative feedback loop in which IL-2 signaling induces $\operatorname{Prdm} 1$ transcription and Blimp-1 represses $I l 2$ transcription in $\mathrm{T}$ cells [15]. Further studies reveal that IL-2 production in Blimp1-deficient $\mathrm{CD}^{+} \mathrm{T}$ cells is upregulated upon TCR stimulation and that Blimp-1 in T cells represses IL-2 production by direct repression of $\mathrm{Il} 2$ and Fos transcription [10, 16]. Furthermore, IL-21-activated STAT3 is a potent inducer of Blimp-1 expression in B cells [93] and CD4 ${ }^{+} \mathrm{T}$ cells [17]. The molecular basis for IL-21-mediated Blimp-1 induction in CD4 ${ }^{+} \mathrm{T}$ cells was clarified by the identification of an IL-21 response element downstream of Prdm1 that binds STAT3 and IRF4, which cooperatively mediate signaling and are required for optimal Prdm1 expression [17].

IRF4 regulates the activation of Blimp-1 expression not only during plasma cell differentiation [94] but also in all effector Treg cells by binding strongly to two previously identified binding sites in the 3 ' region and between exons 5 and 6 of Prdm1 (conserved noncoding sequence 9) [14]. Strong binding of IRF4 to the first introns of $I l 10$ and Ccr6 and binding of Blimp-1 specifically to intron 1 of the Il10 locus were further identified by chromatin immunoprecipitation (ChIP) analysis, suggesting that IRF4 together with Blimp-1 regulates $\mathrm{Il10}$ expression in Treg cells. This study also demonstrated that both IRF4 and Blimp-1 are required for active histone modification and that the IRF4-Blimp-1 axis is essential for the acquisition of Treg cell effector functions [14]. Consistent with these features of effector Treg cells, $\mathrm{T}_{\mathrm{FR}}$ cells express elevated levels of Blimp-1, IL-10, GITR, CTLA-4 and inducible T cell costimulator [58]. Blimp-1 expression specifies a distinct population of effector Treg cells expressing the anti-inflammatory cytokine IL10 and is important for the function and homeostasis of Treg cells.

Blimp-1 deficiency in $\mathrm{T}$ cells results in downregulation of IL-10 production [9, 10], and Blimp-1 is critical for IL-10 expression in Treg cells [14]. Likewise, the IL-27mediated induction of IL-10 in $\mathrm{CD}^{+} \mathrm{T}$ cells depends on Blimp-1 [77]. An early study of IL-27 signal transduction 
for $\mathrm{IL}-10$ production in $\mathrm{CD}_{4}^{+} \mathrm{T}$ cells indicated that the involvement of early growth response gene $2(\mathrm{Egr}-2)$ and Blimp-1 is required for IL-10 production in $\mathrm{CD}^{+} \mathrm{T}$ cells and controls the balance between regulatory and inflammatory cytokines. Furthermore, this study demonstrated that IL-27-induced expression of Egr-2, which binds to the promoter region of $\operatorname{Prdm} 1$ to activate its transcription, is dependent on STAT3 in CD4 ${ }^{+}$T cells [95]. Published studies have further identified an essential function for Blimp-1 in IL-10 production induced by IL27 in inflammatory T helper cells $[18,19]$. Notably, precommitted Th17 cells adopt an IL-27- and IL-12mediated Tr1-like phenotype, producing IL-10 and IFN$\gamma$, by upregulating Blimp-1, while IL-12 signaling results in phosphorylation of STAT4, which binds directly to regulatory elements of Prdm1 [18]. Blimp-1 is also essential for IL-10 expression by Th1 cells through direct binding to a regulatory element in the $I l 10$ locus that is mainly dependent on IL-12-mediated activation of STAT4, which binds to conserved noncoding sequencesin the Prdm1 locus and to the same region (conserved noncoding sequence-9) as Blimp-1 in the Il10 locus. In addition, c-Maf acts synergistically with Blimp-1 to induce IL-10 expression in Th1 cells by binding to the conserved noncoding sequence- 9 region in the Il10 promoter, the same region bound by Blimp-1 and STAT4. c-Maf further enhances Blimp-1 expression by binding to the intron 5 Maf recognition site but not to the promoter of Prdm1, suggesting that it interferes with the repressive function of Bach2 by binding to the same DNA motif [19]. These studies have also demonstrated that IL-27 induces Blimp-1-dependent IL-10 production in Th cells, whereas TGF- $\beta$ antagonizes Blimp-1 expression and mediates IL-10 production driven by c-Maf and AhR [18, 19], consistent with a previous report that TGF- $\beta$ acts as a suppressor of Blimp-1 expression during Th17 differentiation [26]. Therefore, Blimp-1 regulates cytokine production by $\mathrm{T}$ cells via a complex pathway coordinated by diverse transcriptional programs depending on various stimuli from the surrounding environment.

\section{$\mathrm{CD}^{+} \mathrm{T}$ cells}

\section{The molecular regulation of Blimp-1 expression in $C D 8^{+} T$ cells}

The molecular regulation of Blimp-1 expression is distinct in naïve, effector and memory $\mathrm{CD} 8^{+} \mathrm{T}$ cells. Previous studies demonstrated that additional culture of activated $\mathrm{CD}^{+}$T cells in IL-2, IL-4 or IL-12 but not in IL-15 maintains the expression of Blimp-1 [15]. IL-21 induces higher and more rapid expression of $\operatorname{Prdm} 1$ in $\mathrm{T}$ cells than does IL-4 stimulation. The induction of Prdm1 expression by IL-21 was abrogated and diminished in Stat $^{-/-}$and Irf4 $^{-/-} \mathrm{T}$ cells, indicating that IL-21mediated Prdm1 gene expression is dependent on
STAT3 and IRF4. ChIP and luciferase assay experiments revealed that STAT3 and IRF4 broadly cooperate to regulate IL-21-induced Prdm1 gene expression in T cells $[17,69]$. Cui et al. demonstrated that the IL-21-IL-10STAT3 pathway is critical to the differentiation, maturation and self-renewal of memory $\mathrm{CD} 8^{+} \mathrm{T}$ cells during LCMV infection through regulating individual transcription factors including Blimp-1, Eomes and Bcl-6. The amounts of Eomes, T-bet, Bcl- 6 and Blimp- 1 protein in $\mathrm{Stat}^{-/-} \mathrm{CD}^{+} \mathrm{T}$ cells are comparable to those in Stat 3 ${ }^{+/+}$cells at day 8 after LCMV infection, suggesting that STAT3 signaling is not critical to the translational expression of these molecules in the differentiation of effector $\mathrm{CD}^{+} \mathrm{T}$ cells. However, the expression of Blimp-1, Eomes and Bcl-6 was significantly decreased in Stat $3^{-/-}$ memory T cells compared with Stat $^{+/+}$memory cells, suggesting that IL-21-IL10-STAT3 signaling necessarily regulates Blimp-1 expression during the effector-tomemory transition [96].

During DC vaccination, the expression of Blimp-1 was correlated with the number of antigen-specific $\mathrm{T}$ cells. The expression of $\operatorname{Prdm} 1$ was more highly induced in effectors when low numbers $\left(10^{4}\right)$ compared with high $\left(10^{6}\right)$ numbers of OT-I cells were transferred prior to DC vaccination. Moreover, the induction of $\operatorname{Prdm} 1$ was dependent on IL-2, indicating that the IL-2/Blimp-1 axis is a key regulator of SLEC differentiation in vivo in this low-inflammation model of DC immunization [68]. During influenza virus infection, the splenic IL-2R $\alpha$ deficient antigen-specific $\mathrm{CD} 8^{+} \mathrm{T}$ cells fail to develop into $\mathrm{KLRG}^{+} \mathrm{IL}^{-7 \mathrm{R}^{-}}$SLECs and express less Blimp-1 than wild-type cells. However, the differentiated $I l 2 \mathrm{Ra}^{-/-}$ antigen-specific SLECs express high levels of Blimp-1, indicating that IL-2 signaling is not essential for Blimp-1 expression but is required for its optimal expression in $\mathrm{CD}^{+} \mathrm{T}$ cells during virus infection. Moreover, IL-2STAT5 can cooperate with IL-12-STAT4 to induce high amounts of Blimp-1 and SLEC differentiation [97].

The Hippo pathway, a conserved developmental system triggered by cell-cell contact signals to trigger differentiation, induces yes-associated protein degradation and Blimp-1 expression [98]. Rodriguez et al. demonstrated that suppressor of cytokine signaling1 (Socs1) $)^{-1}$ MHC-I-restricted premelanosome protein-1 (Pmel-1) transgenic TCR $\mathrm{CD}^{+}{ }^{+} \mathrm{T}$ cells expressed higher levels of Blimp-1 upon stimulation with cognate self-antigen (mgp10025-33) than did wild type Pmel-1 cells, suggesting that SOCS1 regulates Blimp-1. However, the underlying mechanism of this effect is unknown [99]. Kurachi et al. demonstrated that a basic leucine zipper transcription factor (BATF) is essential for operation of the differentiation checkpoint in early effector $\mathrm{CD}^{+} \mathrm{T}$ cells. BATF binds to regulatory regions in $\operatorname{Prdm} 1$ and many other genes encoding effector transcription factors to 
form a "BATF-centric" interaction network of transcription factors to regulate the differentiation of effector $\mathrm{CD}^{+} \mathrm{T}$ cells [100]. Moreover, BATF overexpression enhances Blimp-1 and granzyme B expression to promote the quality and quantity of virus-specific $\mathrm{CD} 8^{+} \mathrm{T}$ cells during infection. In addition, the IL-21-STAT3-BATF axis cooperates with antigen-induced IRF4 to maintain Blimp1 expression and $\mathrm{CD}^{+} \mathrm{T}$ cell effector functions [101].

Recently, Yamada et al. demonstrated that a deficiency of menin, a tumor suppressor protein, in $\mathrm{CD}^{+} \mathrm{T}$ cells will result in impaired immune responses of antigenspecific $\mathrm{CD}^{+} \mathrm{T}$ cells to infection. Their results revealed that menin inhibits terminal effector differentiation and enhances memory development by suppressing expression of T-bet and Blimp-1 [102]. Although the underlying mechanism by which menin suppresses Blimp-1 expression is unknown, the authors suggest that menin interacts with JunD and acts as a repressor of AP-1.

\section{The molecular regulation of Blimp-1 in $\mathrm{CD}^{+} \mathrm{T}$ cell functions}

Growing evidence suggests that the interactions between Blimp-1 and other factors mediate counter-regulatory influences to produce functional $\mathrm{T}$ cells. After an acute influenza virus infection, the transcriptional profiles of Tbx21, Eomes and Bcl6 are changed in virus-specific Blimp-1-deficient $\mathrm{CD}^{+} \mathrm{T}$ cells, suggesting that Blimp-1 is required for the differentiation of effector $\mathrm{CD} 8^{+} \mathrm{T}$ cells by regulating the transcriptional programs of effector and memory $\mathrm{T}$ cell differentiation [27]. Recently, Xin et al. demonstrated that Blimp-1 cooperates with Tbet to drive effector $\mathrm{CD}^{+} \mathrm{T}$ cell differentiation by regulating overlapping and distinct transcriptional signatures during virus infection. T-bet overexpression partially compensates for KLRG1 expression and downregulates IL-7R and Eomes in Blimp-1-deficient $\mathrm{CD}^{+} \mathrm{T}$ cells during viral antigen-specific SLEC differentiation and memory cell formation. However, T-bet protein expression does not differ significantly between antigen-specific wild-type and Blimp-1-deficient $\mathrm{CD}^{+} \mathrm{T}$ cells during influenza virus infection, indicating that the expression of T-bet protein in $\mathrm{CD}^{+} \mathrm{T}$ cells is largely independent of Blimp-1 [97]. Id2 and Id 3 are expressed by effector CD8 ${ }^{+} \mathrm{T}$ cells and support their survival during the naïve-toeffector cell and effector-to-memory cell transitions, respectively $[103,104]$. Ji et al. demonstrated that Blimp-1 represses Id 3 expression by directly targeting the Id 3 promoter in effector $\mathrm{CD}^{+} \mathrm{T}$ cells. Id3 regulates the survival of SLECs partly through antagonizing the binding of E2A to DNA, suggesting that the Blimp-1-Id3-E2A axis determines the fate of effector $\mathrm{CD} 8^{+} \mathrm{T}$ cells [29]. In addition to Id3, Blimp-1 directly regulates Il2ra and $C d 27$ expression through recruitment of histonemodifying enzymes H3 methyltransferase G9a and
HDAC2, indicating that Blimp-1 acts as an epigenetic regulator to regulate effector $\mathrm{CD}^{+} \mathrm{T}$ cell development in response to an acute virus challenge [70]. Moreover, Blimp-1 directly represses $P d 1$ transcription by regulating expression of nuclear factor of activated $\mathrm{T}$ cells (NFAT)c1, altering local chromatin structure and evicting NFATc1 from its binding sites on the $P d 1$ gene during the early stages of effector $\mathrm{CD}^{+} \mathrm{T}$ cell differentiation after acute virus infection [105].

\section{Genetic disruption of Blimp-1 in T cells and its ef- fect on predisposition to disease}

The role of Blimp-1 in autoimmune diseases, infectious diseases and lymphoid malignancies has been studied intensively.

\section{Animal disease models}

Blimp-1 is expressed in effector T cells and is required for controlling their homeostasis. Mice either lacking Blimp-1 specifically in $\mathrm{T}$ cells or reconstituted with Blimp-1deficient fetal liver cells develop progressive colitis or a lethal wasting disease with increased effector $\mathrm{CD}^{+}$and $\mathrm{CD} 8^{+} \mathrm{T}$ lymphocyte infiltration $[9,10]$. C57BL/6 mice in which Blimp-1 is ablated develop severe colitis. A similar phenotype is observed in NOD mice with $\mathrm{T}$ cell-specific Blimp-1 disruption that have increased Th1/Th17 effector cell populations [35, 39], while transgenic Blimp-1 attenuates the diabetogenic effect of lymphocytes and thereby ameliorates the disease progression of autoimmune diabetes in NOD mice [35]. Blimp-1 is also able to suppress autoimmune encephalomyelitis through downregulation of Th1 and Th17 cells [38].

The function of Blimp-1 has been studied in multiple infectious disease models. During influenza virus infection, deficiency of Blimp-1 in T cells (Prdm $1^{\text {flox/flox }}$ proximal-Lck-Cre) will lead to a delayed recovery from infection and increased cellular infiltration in the lungs, indicating a significant role of Blimp-1 in T cell responses against influenza infection [27]. Although Blimp-1deficient memory $\mathrm{CD}^{+} \mathrm{T}$ cells are capable of providing protection during a second LCMV infection [28], double

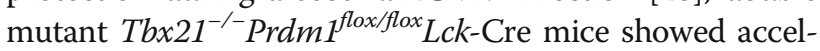
erated weight loss and death during LCMV infection compared with single-mutant and wild-type mice, indicating that Blimp-1 cooperates with T-bet for the differentiation of protective effector $\mathrm{CD}^{+} \mathrm{T}$ cells [97].

Blimp-1 also participates in the development of $\mathrm{T}$ cell lymphoma. High expression of the Itk-Syk oncogene in thymocytes induces Blimp-1 expression regulated by STAT3 and IRF4 cooperation. Furthermore, the high ItkSyk-expressing thymocytes may undergo Blimp-1mediated premature terminal differentiation, leading to the elimination of oncogene-expressing cells at an early developmental stage. In contrast, the expression of 
a

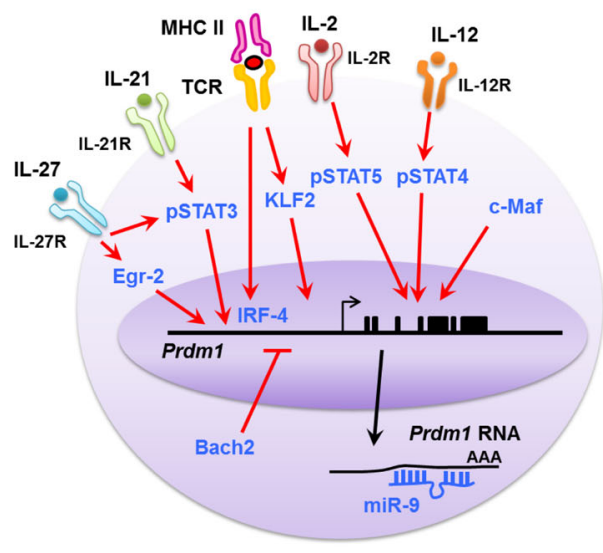

b $\quad$ CD8+ $T$ cells

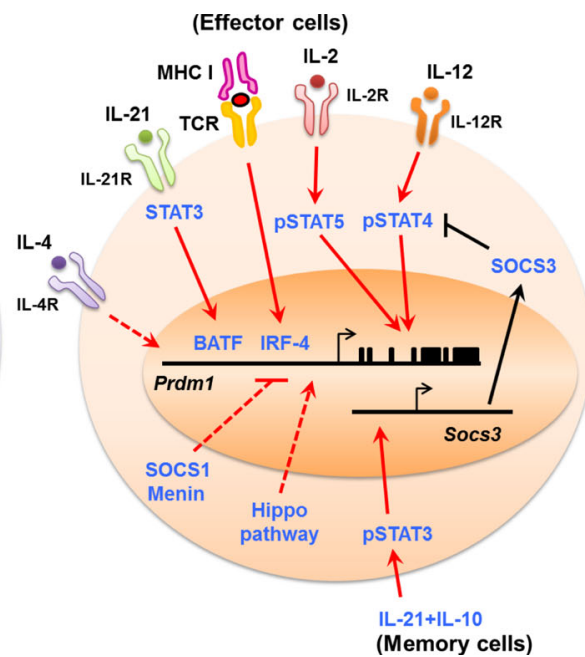

Fig. 1 Regulators for Blimp-1 expression in a CD4 ${ }^{+} \mathrm{T}$ cells and $\mathbf{b}$ CD8 ${ }^{+} \mathrm{T}$ cells. Bach2, BTB and CNC homology 2; BATF, Basic leucine zipper transcription factor; Blimp-1, B lymphocyte-induced maturation protein-1; Egr-2, Early growth response gene 2; IL, Interleukin; IRF4, Interferon regulatory factor 4; KLF2, Kruppel-like factor 2; MHC II, Major histocompatibility complex class II; Prdm1, Positive regulatory domain 1; SOCS, Suppressor of cytokine signaling; STAT, Signal transducers and activators of transcription; TCR, T cell receptor. The solid line indicates direct action by activation of expression of the Prdml gene. The dashed line indicates regulations that require further investigation for underlying mechanisms

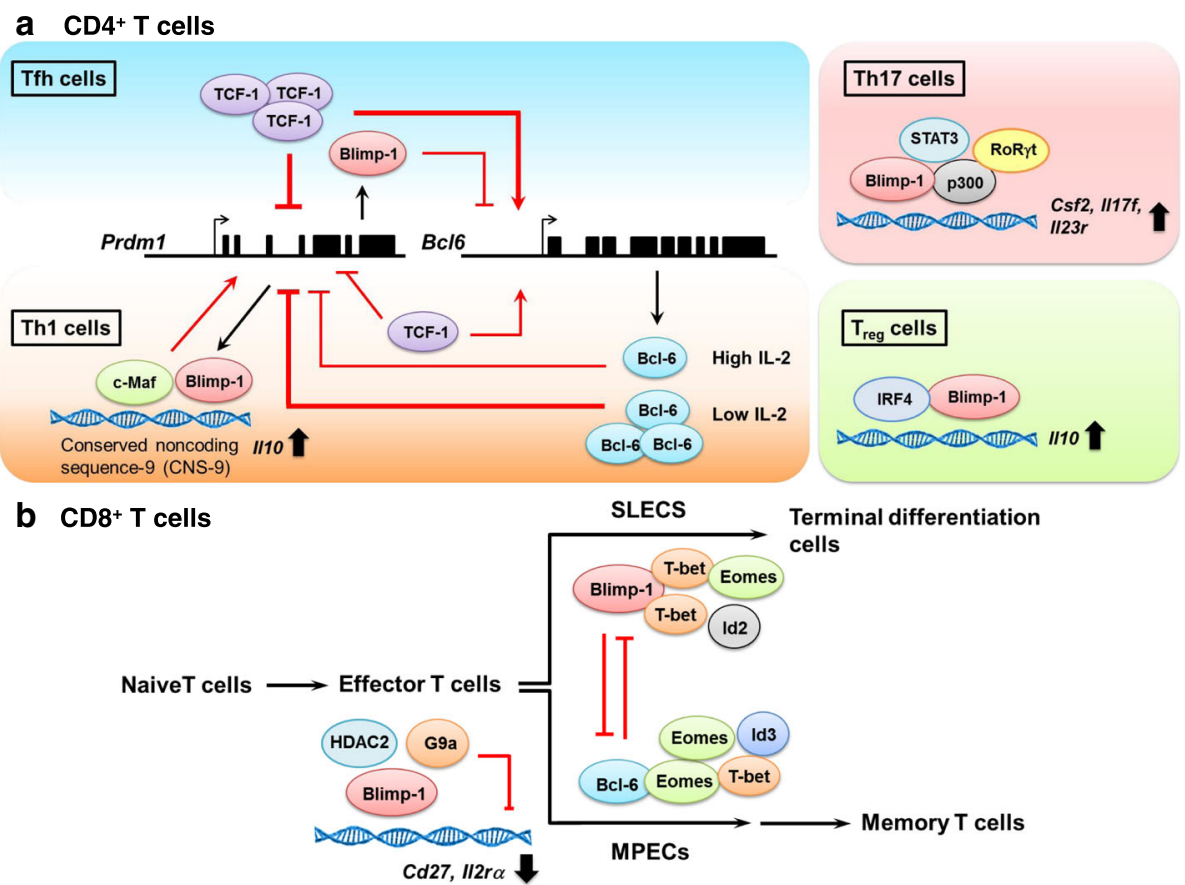

Fig. 2 Blimp-1 cooperates with different molecules to regulate the differentiation and function of a CD4 ${ }^{+} T$ cells and $\mathbf{b} C D 8^{+} T$ cells. Bcl-6, B cell lymphoma-6; Blimp-1, B lymphocyte-induced maturation protein-1; Eomes, Eomesodermin; HDAC2, Histone deacetylase 2; Id2, Inhibitor of DNA binding 2; Id3, Inhibitor of DNA binding 3; IL, Interleukin; IRF4, Interferon regulatory factor 4; MPECs, Memory precursor effector cells; RORyt, Retinoic acid-related orphan receptor $\gamma t$; SLECS, Short-lived effector cells; STAT, Signal transducers and activators of transcription; TCF-1, T cell factor 1; Tfh, Follicular helper T cells; Th, T helper 
Blimp-1 was not observed in lymphocytes expressing low levels of Itk-Syk. Therefore, low and high expression levels of the $I t k-S y k$ fusion transcript induce early and delayed onset of clonal $\mathrm{T}$ cell lymphoma, respectively, through regulating Blimp-1 expression [37].

\section{Human diseases}

BLIMP-1 is considered to be a candidate tumor suppressor gene in lymphoid malignancies. Early studies indicated that BLIMP-1 $\beta$ lacking its PR domain and having a diminished capacity to repress target genes was expressed in myeloma cell lines [106], and mutational inactivation of BLIMP-1 has been identified in a subset of diffuse large B-cell lymphomas [107, 108]. An involvement of BLIMP-1 $\beta$ in $\mathrm{T}$ cell lymphoma was also reported, where a high expression level was correlated with chemotherapy resistance [109]. Another study has also indicated that loss of BLIMP-1 occurs in anaplastic large T-cell lymphomas [110]. In addition, BLIMP-1 is inactivated in extranodal NK/T-cell lymphoma, nasal type (EN-NK/T-NT) where its downregulation is mediated by miR-223, providing a prognostic indicator for evaluating the clinical outcomes of EN-NK/T-NT patients [111]. Recent study reported that infiltration of
BLIMP $-1^{+}$FOXP3 $^{+}$effector Treg cells into tumor can improve prediction of disease recurrence in a cohort of colorectal cancer patients [112]. BLIMP-1 has been further identified as an important factor in $\mathrm{T}$ cell exhaustion during progressive chronic HIV infection. IL-2induced expression of BLIMP-1 is repressed by upregulation of miR-9, which leads to reduced binding of BLIMP-1 to the IL2 promoter. Published studies have further identified that a regulatory miR-9/Blimp-1/IL-2 pathway is impaired in progressive HIV disease [21, 62]. Low expression of PRDM1 was associated with high HIV genome transcription levels in resting $\mathrm{CD} 4^{+} \mathrm{CM} \mathrm{T}$ cells, suggesting that BLIMP-1 might be involved in controlling the HIV reservoirs in the CM T cell subset [63]. Therefore, BLIMP-1 functions as a gatekeeper of $\mathrm{T}$ cell activation and suppression to prevent or dampen autoimmune disease, antiviral responses and antitumor immunity.

\section{Conclusion}

This review has focused on the findings over the past decade that have led to a better understanding of the essential role of Blimp-1 in instructing $\mathrm{T}$ cell destiny and effector functions. Expression of Blimp-1 is observed in

\section{a Blimp-1 target genes :}

In $\mathrm{CD4}^{+} \mathrm{T}$ cells :

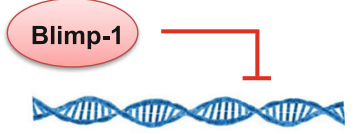

Bcl6, Fos, Ifng, II2, $T b \times 21$

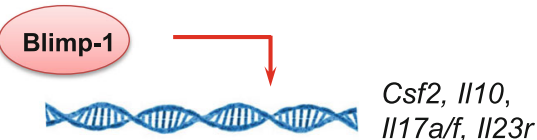

In $\mathrm{CD}^{+} \mathrm{T}$ cells :

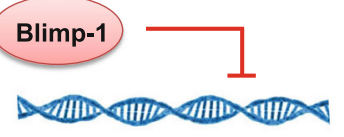

$C d 27, I d 3$

$1 / 2 r \alpha, P d 1$

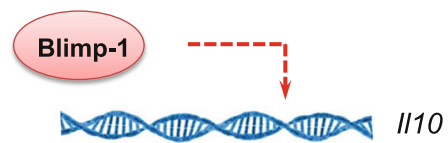

b Blimp-1-mediated regulation of $\mathrm{T}$ cell functions:

\begin{tabular}{|c|c|l|}
\hline CD4 $^{+}$T cells & CD8 $^{+}$T cells & \multicolumn{1}{|c|}{ Functions } \\
\hline$+/-$ & + & Differentiation of effector T cells \\
\hline+ & + & Exhaustion \\
\hline $\mathbf{X}$ & + & Migration of T cells to inflammatory sites \\
\hline $\mathbf{X}$ & - & Cytotoxicity \\
\hline- & - & Proliferation of effector T cells \\
\hline+ & - & Survival of effector T cells \\
\hline+ & + & Production of regulatory cytokine (IL-10) \\
\hline
\end{tabular}

Fig. 3 Overview of Blimp-1-mediated regulations in T cells. a Broad influence of Blimp-1 in the expression of different molecules. Bcl-6, B cell Iymphoma-6; Blimp-1, B lymphocyte-induced maturation protein-1; Id3, Inhibitor of DNA binding 3; IFN- $\gamma$, interferon- $\gamma$; IL, Interleukin; IL2ra, Interleukin 2 receptor subunit alpha; PD-1, Programmed death-1. The solid line indicates direct action. The dashed line indicates regulations that require further investigation for underlying mechanisms. b Blimp-1 regulates divergent functions of T cells. +: Positive regulation; -: Negative regulation; x: Unidentified regulation 
both $\mathrm{CD}_{4}^{+}$and $\mathrm{CD}^{+}{ }^{+} \mathrm{T}$ cells (Fig. 1), and its expression promotes the differentiation and cytokine production of effector $\mathrm{T}$ cells through cooperation with other transcription factors while suppressing the transcriptional signatures of naïve and memory T cells (Fig. 2). Blimp-1 is conventionally regarded as a repressor that regulates $\mathrm{T}$ cell differentiation and function, but notably, Blimp-1 is identified as an enhancer of IL-10 production to finetune the extent of inflammation and injury (Fig. 3). It is intriguing that Blimp-1 together with cooperating transcription factors can function as either an activator or a repressor and can determine the fate of multiple T-cell lineages. Understanding the expression patterns of transcriptional regulators in $\mathrm{T}$ cell subsets suggests that the determination of activation and repression of $\mathrm{T}$ cells is a combinatorial process mediated by these molecules to maintain immune homeostasis. Because Blimp-1 appears to orchestrate cascades of explicit gene expression programs in T lymphocytes, studying Blimp-1 and identifying its target genes has revealed important aspects of this regulatory machinery and may help to provide important insights into the regulation of immune homeostasis and the potential for therapeutic intervention.

\section{Endnote}

${ }^{1}$ Fully capitalized PRDM1 and BLIMP-1 were referred as human gene and protein names, respectively, while only an initial capital letter of $\operatorname{Prdm} 1$ and Blimp-1 were represented as mouse gene and protein names, respectively.

\footnotetext{
Abbreviations

AICD: Activation-induced cell death; Bach2: BTB and CNC homology 2; BATF: Basic leucine zipper transcription factor; Bcl-6: B cell lymphoma-6; Blimp-1: B lymphocyte-induced maturation protein-1; CCR6: C-C chemokine receptor 6; ChIP: Chromatin immunoprecipitation; ChIP-Seq: Chromatin immunoprecipitation with massively parallel sequencing; CKO: Conditional knockout; CM: Central memory; CNS: Central nervous system; CTLA4: Cytolytic T-lymphocyte antigen-4; CXCR5: C-X-C chemokine receptor type 5; DCs: Dendritic cells; DN: Double-negative; DP: Double-positive; Egr-2: Early growth response gene 2; EM: Effector memory; EN-NK/T-NT: Extranodal NKTT cell lymphoma, nasal type; Eomes: Eomesodermin; Foxp3: Forkhead box p3; GATA3: GATA binding protein 3; GFP: Green fluorescent protein; GITR: Glucocorticoid-induced tumor necrosis family related gene; HDAC2: Histone deacetylase 2; Id2: Inhibitor of DNA binding 2; Id3: Inhibitor of DNA binding 3; IFN- $\beta$ : Interferon- $\beta$; IFN- $\gamma$ : Interferon- $\gamma$; IL: Interleukin; IL2ra: Interleukin 2 receptor subunit alpha; IL-7R: IL-7 receptor; IRF4: Interferon regulatory factor 4; Itk-Syk: IL-2-inducible kinase-spleen tyrosine kinase; KLF2: Kruppel-like factor 2; KLRG1: Killer-cell lectin-like receptor G1; LAG3: Lymphocyte activation gene-3; LCMV: Lymphocytic choriomeningitis virus; LPS: Lipopolysaccharide; MOG: Myelin oligodendrocyte glycoprotein; MPECs: Memory precursor effector cells; NFATc: Nuclear factor of activated T cells; NOD mice: Non-obese diabetic mice; PD-1: Programmed death-1; Pmel1: Premelanosome protein-1; Prdm1: Positive regulatory domain 1; RORyt: Retinoic acid-related orphan receptor $ү \mathrm{t}$; SLECs: Short-lived effector cells; SOCS: Suppressor of cytokine signaling; STAT: Signal transducers and activators of transcription; Tat: Transactivator of transcription; TCF-1: T cell factor 1; TCR: T cell receptor; Tfh: Follicular helper T cells; TFR: Follicular regulatory T cells; TGF- $\beta$ : Transforming growth factor- $\beta$; Th: T helper; TIM-3: Tcell immunoglobulin mucin-containing domain-3; TNF: Tumor necrosis factor; Tr1 cells: T regulatory 1 cells; Treg: Regulatory T cells
}

\section{Acknowledgements}

Not applicable.

\section{Funding}

This work was supported by Ministry of Science and Technology grants MOST 103-2320-B-016-017-MY3, and MOST 104-2320-B-016-014-MY3; TriService General Hospital grants TSGH-C105-006-008-S02, TSGH-C106-004006-008-S02, VTA105-T-1-1 and VTA106-T-1-1; and Chi Mei Medical Center grant CMNDMC10501.

\section{Availability of data and materials \\ Not applicable.}

\section{Authors' contributions \\ SHF, LTY and HKS designed the concept and collected information. SHF, LTY, CCC, BLJY and HKS discussed the issues. SHF, LTY and HKS wrote the manuscript. SHF, LTY, CCC, BLJY and HKS edited the manuscript. All authors read and approved the final manuscript.}

\section{Ethics approval and consent to participate}

Not applicable.

\section{Consent for publication}

Not applicable.

\section{Competing interests}

The authors declare that they have no competing interests.

\section{Publisher's Note}

Springer Nature remains neutral with regard to jurisdictional claims in published maps and institutional affiliations.

\section{Author details}

${ }^{1}$ Department and Graduate Institute of Microbiology and Immunology, National Defense Medical Center, 161, Section 6, Min-Chuan East Road, Neihu District, Taipei 11490, Taiwan. ${ }^{2}$ Department of Anesthesiology, Chi Mei Medical Center, Tainan 71104, Taiwan. ${ }^{3}$ Department of Recreation and Health-Care Management, Chia Nan University of Pharmacy and Science, Tainan 71104, Taiwan. ${ }^{4}$ Institute of Cellular and System Medicine, National Health Research Institutes, Zhunan 35053, Taiwan.

Received: 6 April 2017 Accepted: 12 July 2017

Published online: 21 July 2017

\section{References}

1. Keller AD, Maniatis T. Identification and characterization of a novel repressor of beta-interferon gene expression. Genes Dev. 1991;5(5):868-79.

2. Shapiro-Shelef M, Lin Kl, McHeyzer-Williams LJ, Liao J, McHeyzer-Williams MG, Calame K. Blimp-1 is required for the formation of immunoglobulin secreting plasma cells and pre-plasma memory B cells. Immunity. 2003; 19(4):607-20.

3. Turner CA Jr, Mack DH, Davis MM. Blimp-1, a novel zinc finger-containing protein that can drive the maturation of $B$ lymphocytes into immunoglobulin-secreting cells. Cell. 1994;77(2):297-306.

4. Chang DH, Angelin-Duclos C, Calame K. BLIMP-1: trigger for differentiation of myeloid lineage. Nat Immunol. 2000;1(2):169-76.

5. Chang DH, Cattoretti G, Calame KL. The dynamic expression pattern of $B$ lymphocyte induced maturation protein-1 (Blimp-1) during mouse embryonic development. Mech Dev. 2002;117(1-2):305-9.

6. Ohinata Y, Payer B, O'Carroll D, Ancelin K, Ono Y, Sano M, Barton SC, Obukhanych T, Nussenzweig M, Tarakhovsky A, Saitou M, Surani MA. Blimp1 is a critical determinant of the germ cell lineage in mice. Nature. 2005;436(7048):207-13.

7. Robertson EJ, Charatsi I, Joyner CJ, Koonce $\mathrm{CH}$, Morgan M, Islam A, Paterson C, Lejsek E, Arnold SJ, Kallies A, Nutt SL, Bikoff EK. Blimp1 regulates development of the posterior forelimb, caudal pharyngeal arches, heart and sensory vibrissae in mice. Development. 2007;134(24):4335-45.

8. Vincent SD, Dunn NR, Sciammas R, Shapiro-Shalef M, Davis MM, Calame K, Bikoff EK, Robertson EJ. The zinc finger transcriptional repressor Blimp1/ Prdm 1 is dispensable for early axis formation but is required for specification of primordial germ cells in the mouse. Development. 2005; 132(6):1315-25. 
9. Kallies A, Hawkins ED, Belz GT, Metcalf D, Hommel M, Corcoran LM, Hodgkin PD, Nutt SL. Transcriptional repressor Blimp-1 is essential for T cell homeostasis and self-tolerance. Nat Immunol. 2006;7(5):466-74.

10. Martins GA, Cimmino L, Shapiro-Shelef M, Szabolcs M, Herron A, Magnusdottir E, Calame K. Transcriptional repressor Blimp-1 regulates T cell homeostasis and function. Nat Immunol. 2006;7(5):457-65.

11. Cimmino L, Martins GA, Liao J, Magnusdottir E, Grunig G, Perez RK, Calame KL. Blimp-1 Attenuates Th1 Differentiation by Repression of ifng, tbx21, and bcl6 Gene Expression. J Immunol. 2008;181(4):2338-47.

12. Johnston RJ, Poholek AC, DiToro D, Yusuf I, Eto D, Barnett B, Dent AL, Craft J, Crotty S. Bcl6 and Blimp-1 are reciprocal and antagonistic regulators of T follicular helper cell differentiation. Science (New York, N.Y.). 2009;325(5943): 1006-10.

13. Nurieva Rl, Chung Y, Hwang D, Yang XO, Kang HS, Ma L, Wang YH, Watowich SS, Jetten AM, Tian Q, Dong C. Generation of T follicular helper cells is mediated by interleukin-21 but independent of Thelper 1, 2, or 17 cell lineages. Immunity. 2008;29(1):138-49.

14. Cretney E, Xin A, Shi W, Minnich M, Masson F, Miasari M, Belz GT, Smyth GK, Busslinger M, Nutt SL, Kallies A. The transcription factors Blimp-1 and IRF4 jointly control the differentiation and function of effector regulatory $T$ cells. Nat Immunol. 2011;12(4):304-11.

15. Gong D, Malek TR. Cytokine-Dependent Blimp-1 Expression in Activated T Cells Inhibits IL-2 Production. J Immunol. 2006;178(1):242-52.

16. Martins GA, Cimmino L, Liao J, Magnusdottir E, Calame K. Blimp-1 directly represses $\| 2$ and the 112 activator Fos, attenuating $T$ cell proliferation and survival. J Exp Med. 2008;205(9):1959-65.

17. Kwon H, Thierry-Mieg D, Thierry-Mieg J, Kim HP, Oh J, Tunyaplin C, Carotta S, Donovan CE, Goldman ML, Tailor P, Ozato K, Levy DE, Nutt SL, Calame K, Leonard WJ. Analysis of interleukin-21-induced Prdm1 gene regulation reveals functional cooperation of STAT3 and IRF4 transcription factors. Immunity. 2009;31(6):941-52.

18. Heinemann C, Heink S, Petermann F, Vasanthakumar A, Rothhammer V Doorduijn E, Mitsdoerffer M, Sie C, Prazeres da Costa O, Buch T, Hemmer B, Oukka M, Kallies A, Korn T. IL-27 and IL-12 oppose pro-inflammatory IL-23 in CD4+ T cells by inducing Blimp1. Nat Commun. 2014;5:3770.

19. Neumann C, Heinrich F, Neumann K, Junghans V, Mashreghi MF, Ahlers J, Janke M, Rudolph C, Mockel-Tenbrinck N, Kuhl AA, Heimesaat MM, Esser C, Im SH, Radbruch A, Rutz S, Scheffold A. Role of Blimp-1 in programing Th effector cells into IL-10 producers. J Exp Med. 2014;211(9):1807-19.

20. Kaech SM, Cui W. Transcriptional control of effector and memory CD8+ T cell differentiation. Nat Rev Immunol. 2012;12(11):749-61.

21. Thaventhiran JE, Fearon DT. Control of HIV infection: escape from the shadow of Blimp-1. Eur J Immunol. 2013;43(2):323-6.

22. Lazarevic V, Glimcher LH, Lord GM. T-bet: a bridge between innate and adaptive immunity. Nat Rev Immunol. 2013;13(11):777-89.

23. Crotty S, Johnston RJ, Schoenberger SP. Effectors and memories: $\mathrm{BCl}-6$ and Blimp-1 in T and B lymphocyte differentiation. Nat Immunol. 2010;11(2):114-20.

24. John SA, Garrett-Sinha LA. Blimp1: a conserved transcriptional repressor critical for differentiation of many tissues. Exp Cell Res. 2009;315(7):1077-84.

25. Tabrizifard S, Olaru A, Plotkin J, Fallahi-Sichani M, Livak F, Petrie HT. Analysis of transcription factor expression during discrete stages of postnatal thymocyte differentiation. J Immunol. 2004;173(2):1094-102.

26. Salehi S, Bankoti R, Benevides L, Willen J, Couse M, Silva JS, Dhall D, Meffre E, Targan S, Martins GA. B lymphocyte-induced maturation protein-1 contributes to intestinal mucosa homeostasis by limiting the number of IL17-producing CD4+ T cells. J Immunol. 2012;189(12):5682-93.

27. Kallies A, Xin A, Belz GT, Nutt SL. Blimp-1 transcription factor is required for the differentiation of effector CD8(+) T cells and memory responses. Immunity. 2009;31(2):283-95.

28. Rutishauser RL, Martins GA, Kalachikov S, Chandele A, Parish IA, Meffre E, Jacob J, Calame K, Kaech SM. Transcriptional repressor Blimp-1 promotes CD8(+) T cell terminal differentiation and represses the acquisition of central memory T cell properties. Immunity. 2009;31(2):296-308.

29. Ji Y, Pos Z, Rao M, Klebanoff CA, Yu Z, Sukumar M, Reger RN, Palmer DC, Borman ZA, Muranski P, Wang E, Schrump DS, Marincola FM, Restifo NP, Gattinoni L. Repression of the DNA-binding inhibitor Id3 by Blimp-1 limits the formation of memory CD8+ T cells. Nat Immunol. 2011;12(12):1230-7.

30. Intlekofer AM, Takemoto N, Kao C, Banerjee A, Schambach F, Northrop JK, Shen H, Wherry EJ, Reiner SL. Requirement for T-bet in the aberrant differentiation of unhelped memory CD8+ T cells. J Exp Med. 2007:204(9): 2015-21.
31. Shin H, Blackburn SD, Intlekofer AM, Kao C, Angelosanto JM, Reiner SL, Wherry EJ. A role for the transcriptional repressor Blimp-1 in CD8(+) T cell exhaustion during chronic viral infection. Immunity. 2009;31(2):309-20.

32. Havenith $\mathrm{SH}$, Yong SL, Henson SM, Piet B, Idu MM, Koch SD, Jonkers RE, Kragten NA, Akbar AN, van Lier RA, ten Berge IJ. Analysis of stem-cell-like properties of human CD161++IL-18Ralpha+ memory CD8+ T cells. Int Immunol. 2012;24(10):625-36.

33. Lee N, You S, Shin MS, Lee WW, Kang KS, Kim SH, Kim WU, Homer RJ, Kang MJ, Montgomery RR, Dela Cruz CS, Shaw AC, Lee PJ, Chupp GL, Hwang D, Kang I. IL-6 receptor alpha defines effector memory CD8+ T cells producing Th2 cytokines and expanding in asthma. Am J Respir Crit Care Med. 2014; 190(12):1383-94.

34. Sforza F, Nicoli F, Gallerani E, Finessi V, Reali E, Cafaro A, Caputo A, Ensoli B, Gavioli R. HIV-1 Tat affects the programming and functionality of human CD8(+) T cells by modulating the expression of T-box transcription factors. AIDS. 2014;28(12):1729-38.

35. Lin MH, Chou FC, Yeh LT, Fu SH, Chiou HY, Lin Kl, Chang DM, Sytwu HK. B lymphocyte-induced maturation protein 1 (BLIMP-1) attenuates autoimmune diabetes in NOD mice by suppressing Th1 and Th17 cells. Diabetologia. 2013;56(1):136-46.

36. Jain $R$, Chen $Y$, Kanno $Y$, Joyce-Shaikh B, Vahedi G, Hirahara K, Blumenschein WM, Sukumar S, Haines CJ, Sadekova S, McClanahan TK, McGeachy MJ, O'Shea JJ, Cua DJ. Interleukin-23-Induced Transcription Factor Blimp-1 Promotes Pathogenicity of T Helper 17 Cells. Immunity. 2016;44(1):131-42.

37. Bach MP, Hug E, Werner M, Holch J, Sprissler C, Pechloff K, Zirlik K, Zeiser R, Dierks C, Ruland J, Jumaa H. Premature terminal differentiation protects from deregulated lymphocyte activation by ITK-Syk. J Immunol. 2014;192(3):1024-33.

38. Lin MH, Yeh LT, Chen SJ, Chiou HY, Chu CC, Yen LB, Lin Kl, Chang DM, Sytwu HK. T cell-specific BLIMP-1 deficiency exacerbates experimental autoimmune encephalomyelitis in nonobese diabetic mice by increasing Th1 and Th17 cells. Clin Immunol. 2014;151(2):101-13.

39. Fu SH, Lin MH, Yeh LT, Wang YL, Chien MW, Lin SH, Chang DM, Sytwu HK. Targeting tumour necrosis factor receptor 1 assembly reverses Th17mediated colitis through boosting a Th2 response. Gut. 2015;64(5):765-75.

40. Hua L, Yao S, Pham D, Jiang L, Wright J, Sawant D, Dent AL, Braciale TJ, Kaplan MH, Sun J. Cytokine-dependent induction of CD4+ T cells with cytotoxic potential during influenza virus infection. J Virol. 2013;87(21): 11884-93.

41. Parish IA, Marshall HD, Staron MM, Lang PA, Brustle A, Chen JH, Cui W, Tsui YC, Perry C, Laidlaw BJ, Ohashi PS, Weaver CT, Kaech SM. Chronic viral infection promotes sustained Th1-derived immunoregulatory IL-10 via BLIMP-1. J Clin Invest. 2014;124(8):3455-68.

42. Kaczmarek Michaels K, Natarajan M, Euler Z, Alter G, Viglianti G, Henderson AJ. Blimp-1, an intrinsic factor that represses HIV-1 proviral transcription in memory CD4+ T cells. J Immunol. 2015;194(7):3267-74

43. O'Shea JJ, Paul WE. Mechanisms underlying lineage commitment and plasticity of helper CD4+ T cells. Science (New York, N.Y.). 2010;327(5969): 1098-102.

44. Crotty S. T follicular helper cell differentiation, function, and roles in disease. Immunity. 2014;41(4):529-42.

45. Oestreich KJ, Mohn SE, Weinmann AS. Molecular mechanisms that control the expression and activity of BCl-6 in TH1 cells to regulate flexibility with a TFH-like gene profile. Nat Immunol. 2012;13(4):405-11.

46. Wang L, van Panhuys N, Hu-Li J, Kim S, Le Gros G, Min B. Blimp-1 induced by IL-4 plays a critical role in suppressing IL-2 production in activated CD4 T cells. J Immunol. 2008;181(8):5249-56.

47. Sogo T, Kawahara M, Ueda H, Otsu M, Onodera M, Nakauchi H, Nagamune T. T cell growth control using hapten-specific antibody/interleukin-2 receptor chimera. Cytokine. 2009;46(1):127-36.

48. Moore KW, de Waal MR, Coffman RL, O'Garra A. Interleukin-10 and the interleukin-10 receptor. Annu Rev Immunol. 2001;19:683-765.

49. Jankovic D, Kugler DG, Sher A. IL-10 production by CD4+ effector T cells: a mechanism for self-regulation. Mucosal Immunol. 2010;3(3):239-46.

50. Anderson CF, Oukka M, Kuchroo VJ, Sacks D. CD4(+)CD25(-)Foxp3(-) Th1 cells are the source of IL-10-mediated immune suppression in chronic cutaneous leishmaniasis. J Exp Med. 2007;204(2):285-97.

51. Kemp KL, Levin SD, Stein PL. Lck regulates IL-10 expression in memory-like Th1 cells. Eur J Immunol. 2010:40(11):3210-9.

52. Zander RA, Guthmiller JJ, Graham AC, Pope RL, Burke BE, Carr DJ, Butler NS. Type I Interferons Induce T Regulatory 1 Responses and Restrict Humoral Immunity during Experimental Malaria. PLoS Pathog. 2016;12(10):e1005945. 
53. Awasthi A, Carrier Y, Peron JP, Bettelli E, Kamanaka M, Flavell RA, Kuchroo VK, Oukka M, Weiner HL. A dominant function for interleukin 27 in generating interleukin 10-producing anti-inflammatory T cells. Nat Immunol. 2007:8(12):1380-9.

54. Stumhofer JS, Silver JS, Laurence A, Porrett PM, Harris TH, Turka LA, Ernst M, Saris CJ, O'Shea JJ, Hunter CA. Interleukins 27 and 6 induce STAT3-mediated T cell production of interleukin 10. Nat Immunol. 2007;8(12):1363-71.

55. Montes de Oca M, Kumar R, de Labastida Rivera F, Amante FH, Sheel M, Faleiro RJ, Bunn PT, Best SE, Beattie L, Ng SS, Edwards CL, Muller W, Cretney E, Nutt SL, Smyth MJ, Haque A, Hill GR, Sundar S, Kallies A, Engwerda CR. Blimp-1-Dependent IL-10 Production by Tr1 Cells Regulates TNF-Mediated Tissue Pathology. PLoS Pathog. 2016;12(1): e1005398.

56. Zheng Y, Josefowicz SZ, Kas A, Chu TT, Gavin MA, Rudensky AY. Genomewide analysis of Foxp3 target genes in developing and mature regulatory $T$ cells. Nature. 2007;445(7130):936-40.

57. Cretney E, Kallies A, Nutt SL. Differentiation and function of Foxp3(+) effector regulatory T cells. Trends Immunol. 2013;34(2):74-80.

58. Linterman MA, Pierson W, Lee SK, Kallies A, Kawamoto S, Rayner TF, Srivastava M, Divekar DP, Beaton L, Hogan JJ, Fagarasan S, Liston A, Smith $K G$, Vinuesa CG. Foxp3+ follicular regulatory $T$ cells control the germinal center response. Nat Med. 2011;17(8):975-82.

59. Bedoya F, Cheng GS, Leibow A, Zakhary N, Weissler K, Garcia V, Aitken M, Kropf E, Garlick DS, Wherry EJ, Erikson J, Caton AJ. Viral antigen induces differentiation of Foxp3+ natural regulatory T cells in influenza virusinfected mice. J Immunol. 2013;190(12):6115-25.

60. Hu M, Wang C, Zhang GY, Saito M, Wang YM, Fernandez MA, Wang Y, Wu H, Hawthorne WJ, Jones C, O'Connell PJ, Sparwasser T, Bishop GA, Sharland $\mathrm{AF}$, Alexander SI. Infiltrating Foxp3(+) regulatory T cells from spontaneously tolerant kidney allografts demonstrate donor-specific tolerance. Am J Transplant. 2013;13(11):2819-30.

61. Collins $\mathrm{MH}$, Henderson AJ. Transcriptional regulation and T cell exhaustion. Curr Opin HIV AIDS. 2014;9(5):459-63.

62. Seddiki N, Phetsouphanh C, Swaminathan S, Xu Y, Rao S, Li J, Sutcliffe EL, Denyer G, Finlayson R, Gelgor L, Cooper DA, Zaunders J, Kelleher AD. The microRNA-9/B-lymphocyte-induced maturation protein-1/IL-2 axis is differentially regulated in progressive HIV infection. Eur J Immunol. 2013; 43(2):510-20.

63. de Masson A, Kirilovsky A, Zoorob R, Avettand-Fenoel V, Morin V, Oudin A, Descours B, Rouzioux C, Autran B. Blimp-1 overexpression is associated with low HIV-1 reservoir and transcription levels in central memory CD4+ T cells from elite controllers. AIDS. 2014;28(11):1567-77.

64. Che KF, Shankar EM, Muthu S, Zandi S, Sigvardsson M, Hinkula J, Messmer D, Larsson M. p38 Mitogen-activated protein kinase/signal transducer and activator of transcription-3 pathway signaling regulates expression of inhibitory molecules in T cells activated by HIV-1-exposed dendritic cells. Mol Med. 2012;18:1169-82.

65. Shankar EM, Che KF, Messmer D, Lifson JD, Larsson M. Expression of a broad array of negative costimulatory molecules and Blimp-1 in T cells following priming by HIV-1 pulsed dendritic cells. Mol Med. 2011;17(3-4):229-40.

66. Thiele S, Wittmann J, Jack HM, Pahl A. miR-9 enhances IL-2 production in activated human CD4(+) T cells by repressing Blimp-1. Eur J Immunol. 2012; 42(8):2100-8.

67. Hwang S, Cobb DA, Bhadra R, Youngblood B, Khan IA. Blimp-1-mediated CD4 T cell exhaustion causes CD8 T cell dysfunction during chronic toxoplasmosis. J Exp Med. 2016;213(9):1799-818.

68. Boulet S, Daudelin JF, Labrecque N. IL-2 induction of Blimp-1 is a key in vivo signal for CD8+ short-lived effector T cell differentiation. J Immunol. 2014; 193(4):1847-54.

69. Raczkowski F, Ritter J, Heesch K, Schumacher V, Guralnik A, Hocker L, Raifer H, Klein M, Bopp T, Harb H, Kesper DA, Pfefferle PI, Grusdat M, Lang PA, Mittrucker HW, Huber M. The transcription factor Interferon Regulatory Factor 4 is required for the generation of protective effector CD8+ T cells. Proc Natl Acad Sci U S A. 2013;110(37):15019-24.

70. Shin HM, Kapoor VN, Guan T, Kaech SM, Welsh RM, Berg LJ. Epigenetic modifications induced by Blimp-1 Regulate CD8(+) T cell memory progression during acute virus infection. Immunity. 2013;39(4):661-75.

71. Stelekati E, Shin H, Doering TA, Dolfi DV, Ziegler CG, Beiting DP, Dawson L, Liboon J, Wolski D, Ali MA, Katsikis PD, Shen H, Roos DS, Haining WN, Lauer GM, Wherry EJ. Bystander chronic infection negatively impacts development of CD8(+) T cell memory. Immunity. 2014;40(5):801-13.
72. Boyman O, Sprent J. The role of interleukin-2 during homeostasis and activation of the immune system. Nat Rev Immunol. 2012;12(3):180-90.

73. Duttagupta PA, Boesteanu AC, Katsikis PD. Costimulation signals for memory CD8+ T cells during viral infections. Crit Rev Immunol. 2009;29(6): 469-86.

74. Dolfi DV, Boesteanu AC, Petrovas C, Xia D, Butz EA, Katsikis PD. Late signals from CD27 prevent Fas-dependent apoptosis of primary CD8+ T cells. J Immunol. 2008;180(5):2912-21.

75. Peperzak V, Xiao Y, Veraar EA, Borst J. CD27 sustains survival of CTLs in virusinfected nonlymphoid tissue in mice by inducing autocrine IL-2 production. J Clin Invest. 2010;120(1):168-78.

76. Sun J, Madan R, Karp CL, Braciale TJ. Effector T cells control lung inflammation during acute influenza virus infection by producing IL-10. Nat Med. 2009;15(3):277-84.

77. Sun J, Dodd H, Moser EK, Sharma R, Braciale TJ. CD4+ T cell help and innate-derived IL-27 induce Blimp-1-dependent IL-10 production by antiviral CTLs. Nat Immunol. 2011;12(4):327-34.

78. Jiang L, Yao S, Huang S, Wright J, Braciale TJ, Sun J. Type I IFN signaling facilitates the development of IL-10-producing effector CD8+ T cells during murine influenza virus infection. Eur J Immunol. 2016;46(12):2778-88.

79. Morgan MA, Magnusdottir E, Kuo TC, Tunyaplin C, Harper J, Arnold SJ, Calame K, Robertson EJ, Bikoff EK. Blimp-1/Prdm1 alternative promoter usage during mouse development and plasma cell differentiation. Mol Cell Biol. 2009;29(21):5813-27.

80. Tsukumo S, Unno M, Muto A, Takeuchi A, Kometani K, Kurosaki T, Igarashi K, Saito T. Bach2 maintains T cells in a naive state by suppressing effector memory-related genes. Proc Natl Acad Sci U S A. 2013;110(26):10735-40.

81. Roychoudhuri R, Hirahara K, Mousavi K, Clever D, Klebanoff CA, Bonelli M, Sciume G, Zare H, Vahedi G, Dema B, Yu Z, Liu H, Takahashi H, Rao M, Muranski P, Crompton JG, Punkosdy G, Bedognetti D, Wang E, Hoffmann V, Rivera J, Marincola FM, Nakamura A, Sartorelli V, Kanno Y, Gattinoni L, Muto A, Igarashi K, O'Shea JJ, Restifo NP. BACH2 represses effector programs to stabilize T(reg)-mediated immune homeostasis. Nature. 2013;498(7455):50610.

82. Kim EH, Gasper DJ, Lee SH, Plisch EH, Svaren J, Suresh M. Bach2 regulates homeostasis of Foxp3+ regulatory $T$ cells and protects against fatal lung disease in mice. J Immunol. 2014;192(3):985-95.

83. Fazilleau N, McHeyzer-Williams $L$, Rosen $\mathrm{H}$, McHeyzer-Williams MG. The function of follicular helper $\mathrm{T}$ cells is regulated by the strength of $\mathrm{T}$ cell antigen receptor binding. Nat Immunol. 2009;10(4):375-84.

84. Kusam S, Toney LM, Sato H, Dent AL. Inhibition of Th2 differentiation and GATA-3 expression by BCL-6. J Immunol. 2003;170(5):2435-41.

85. Arima M, Toyama H, Ichii H, Kojima S, Okada S, Hatano M, Cheng G, Kubo M, Fukuda T, Tokuhisa T. A putative silencer element in the IL-5 gene recognized by Bcl6. J Immunol. 2002;169(2):829-36.

86. Yu D, Rao S, Tsai LM, Lee SK, He Y, Sutcliffe EL, Srivastava M, Linterman M, Zheng L, Simpson N, Ellyard JI, Parish IA, Ma CS, Li QJ, Parish CR, Mackay CR, Vinuesa CG. The transcriptional repressor $\mathrm{BCl}-6$ directs $T$ follicular helper cell lineage commitment. Immunity. 2009;31(3):457-68.

87. Johnston RJ, Choi YS, Diamond JA, Yang JA, Crotty S. STAT5 is a potent negative regulator of TFH cell differentiation. J Exp Med. 2012;209(2): 243-50.

88. Nurieva Rl, Podd A, Chen Y, Alekseev AM, Yu M, Qi X, Huang H, Wen R, Wang J, Li HS, Watowich SS, Qi H, Dong C, Wang D. STAT5 protein negatively regulates $T$ follicular helper (Tfh) cell generation and function. J Biol Chem. 2012;287(14):11234-9.

89. Lee JY, Skon CN, Lee YJ, Oh S, Taylor JJ, Malhotra D, Jenkins MK, Rosenfeld MG, Hogquist KA, Jameson SC. The transcription factor KLF2 restrains CD4(+) T follicular helper cell differentiation. Immunity. 2015;42(2):252-64.

90. Choi YS, Gullicksrud JA, Xing S, Zeng Z, Shan Q, Li F, Love PE, Peng W, Xue $\mathrm{HH}$, Crotty S. LEF-1 and TCF-1 orchestrate T(FH) differentiation by regulating differentiation circuits upstream of the transcriptional repressor Bcl6. Nat Immunol. 2015;16(9):980-90.

91. Wu T, Shin HM, Moseman EA, Ji Y, Huang B, Harly C, Sen JM, Berg LJ, Gattinoni L, McGavern DB, Schwartzberg PL. TCF1 Is Required for the T Follicular Helper Cell Response to Viral Infection. Cell Rep. 2015;12(12): 2099-110.

92. Xu L, Cao Y, Xie Z, Huang Q, Bai Q, Yang X, He R, Hao Y, Wang H, Zhao T, Fan Z, Qin A, Ye J, Zhou X, Ye L, Wu Y. The transcription factor TCF-1 initiates the differentiation of $\mathrm{T}(\mathrm{FH})$ cells during acute viral infection. Nat Immunol. 2015;16(9):991-9. 
93. Avery DT, Deenick EK, Ma CS, Suryani S, Simpson N, Chew GY, Chan TD, Palendira U, Bustamante J, Boisson-Dupuis S, Choo S, Bleasel KE, Peake J, King C, French MA, Engelhard D, Al-Hajjar S, Al-Muhsen S, Magdorf K, Roesler J, Arkwright PD, Hissaria P, Riminton DS, Wong M, Brink R, Fulcher DA, Casanova JL, Cook MC, Tangye SG. B cell-intrinsic signaling through IL21 receptor and STAT3 is required for establishing long-lived antibody responses in humans. J Exp Med. 2010;207(1):155-71.

94. Sciammas R, Shaffer AL, Schatz JH, Zhao H, Staudt LM, Singh H. Graded expression of interferon regulatory factor-4 coordinates isotype switching with plasma cell differentiation. Immunity. 2006;25(2):225-36.

95. Iwasaki Y, Fujio K, Okamura T, Yanai A, Sumitomo S, Shoda H, Tamura T, Yoshida $\mathrm{H}$, Charnay $\mathrm{P}$, Yamamoto K. Egr-2 transcription factor is required for Blimp-1-mediated IL-10 production in IL-27-stimulated CD4+ T cells. Eur J Immunol. 2013;43(4):1063-73.

96. Cui W, Liu Y, Weinstein JS, Craft J, Kaech SM. An interleukin-21-interleukin10-STAT3 pathway is critical for functional maturation of memory CD8+ T cells. Immunity. 2011;35(5):792-805.

97. Xin A, Masson F, Liao Y, Preston S, Guan T, Gloury R, Olshansky M, Lin JX, Li P, Speed TP, Smyth GK, Ernst M, Leonard WJ, Pellegrini M, Kaech SM, Nutt SL, Shi W, Belz GT, Kallies A. A molecular threshold for effector CD8(+) T cell differentiation controlled by transcription factors Blimp-1 and T-bet. Nat Immunol. 2016;17(4):422-32.

98. Thaventhiran JE, Hoffmann A, Magiera L, de la Roche M, Lingel H, BrunnerWeinzierl M, Fearon DT. Activation of the Hippo pathway by CTLA-4 regulates the expression of Blimp-1 in the CD8+ T cell. Proc Natl Acad Sci U S A. 2012;109(33):E2223-9.

99. Rodriguez GM, D'Urbano D, Bobbala D, Chen XL, Yeganeh M, Ramanathan S, llangumaran S. SOCS1 prevents potentially skin-reactive cytotoxic T lymphocytes from gaining the ability to cause inflammatory lesions. J Invest Dermatol. 2013;133(8):2013-22.

100. Kurachi M, Barnitz RA, Yosef N, Odorizzi PM, Dilorio MA, Lemieux ME, Yates K, Godec J, Klatt MG, Regev A, Wherry EJ, Haining WN. The transcription factor BATF operates as an essential differentiation checkpoint in early effector CD8+ T cells. Nat Immunol. 2014;15(4):373-83.

101. Xin G, Schauder DM, Lainez B, Weinstein JS, Dai Z, Chen Y, Esplugues E, Wen R, Wang D, Parish IA, Zajac AJ, Craft J, Cui W. A Critical Role of IL-21Induced BATF in Sustaining CD8-T-Cell-Mediated Chronic Viral Control. Cell Rep. 2015;13(6):1118-24.

102. Yamada T, Kanoh M, Nabe S, Yasuoka T, Suzuki J, Matsumoto A, Kuwahara M, Maruyama S, Fujimoto T, Sakisuka R, Yasukawa M, Yamashita M. Menin Plays a Critical Role in the Regulation of the Antigen-Specific CD8+ T Cell Response upon Listeria Infection. J Immunol. 2016;197(10):4079-89.

103. Cannarile MA, Lind NA, Rivera R, Sheridan AD, Camfield KA, Wu BB, Cheung KP, Ding Z, Goldrath AW. Transcriptional regulator Id2 mediates CD8+ T cell immunity. Nat Immunol. 2006;7(12):1317-25.

104. Yang CY, Best JA, Knell J, Yang E, Sheridan AD, Jesionek AK, Li HS, Rivera RR, Lind KC, D'Cruz LM, Watowich SS, Murre C, Goldrath AW. The transcriptional regulators $\mathrm{Id} 2$ and $\mathrm{Id} 3$ control the formation of distinct memory CD8+ T cell subsets. Nat Immunol. 2011;12(12):1221-9.

105. Lu P, Youngblood BA, Austin JW, Mohammed AU, Butler R, Ahmed R, Boss JM. Blimp-1 represses CD8 T cell expression of PD-1 using a feed-forward transcriptional circuit during acute viral infection. J Exp Med. 2014;211(3): 515-27.

106. Gyory I, Fejer G, Ghosh N, Seto E, Wright KL. Identification of a functionally impaired positive regulatory domain I binding factor 1 transcription repressor in myeloma cell lines. J Immunol. 2003;170(6):3125-33.

107. Tam W, Gomez M, Chadburn A, Lee JW, Chan WC, Knowles DM. Mutational analysis of PRDM1 indicates a tumor-suppressor role in diffuse large B-cell lymphomas. Blood. 2006;107(10):4090-100.

108. Pasqualucci L, Compagno M, Houldsworth J, Monti S, Grunn A, Nandula SV, Aster JC, Murty W, Shipp MA, Dalla-Favera R. Inactivation of the PRDM1/BLIMP1 gene in diffuse large B cell lymphoma. J Exp Med. 2006;203(2):311-7.

109. Zhao WL, Liu YY, Zhang QL, Wang L, Leboeuf C, Zhang YW, Ma J, Garcia JF, Song YP, Li JM, Shen ZX, Chen Z, Janin A, Chen SJ. PRDM1 is involved in chemoresistance of T-cell lymphoma and down-regulated by the proteasome inhibitor. Blood. 2008;111(7):3867-71.

110. Tabbo F, Ponzoni M, Rabadan R, Bertoni F, Inghirami G, European TCLSG. Beyond NPM-anaplastic lymphoma kinase driven lymphomagenesis: alternative drivers in anaplastic large cell lymphoma. Curr Opin Hematol. 2013;20(4):374-81.
111. Liang L, Nong L, Zhang S, Zhao J, Ti H, Dong Y, Zhang B, Li T. The downregulation of PRDM1/Blimp-1 is associated with aberrant expression of miR-223 in extranodal NK/T-cell lymphoma, nasal type. J Exp Clin Cancer Res. 2014;33:7.

112. Ward-Hartstonge KA, McCall UL, McCulloch TR, Kamps AK, Girardin A, Cretney E, Munro FM, Kemp RA. Inclusion of BLIMP-1+ effector regulatory T cells improves the Immunoscore in a cohort of New Zealand colorectal cancer patients: a pilot study. Cancer Immunol Immunother. 2017;66(4):515-22.

\section{Submit your next manuscript to BioMed Central and we will help you at every step:}

- We accept pre-submission inquiries

- Our selector tool helps you to find the most relevant journal

- We provide round the clock customer support

- Convenient online submission

- Thorough peer review

- Inclusion in PubMed and all major indexing services

- Maximum visibility for your research

Submit your manuscript at www.biomedcentral.com/submit
C Biomed Central 